\title{
Tangled Transmissions: The Differentiation of Historic Telegraph and Telephone Lines through Material Culture
}

\author{
JOSHUA BIRndORF ${ }^{1}$ AND SCOTT E. INGRAM ${ }^{1}$ \\ ${ }^{1}$ Colorado College
}

\begin{abstract}
Historic telegraph and telephone material culture are frequently encountered but seldom differentiated during archaeological site and survey work in Colorado. The poles, wires, and insulators that comprise these cultural resources are often recorded simply as transmission lines. The research reported here is the first archaeologically focused comparative study of telegraph and telephone material culture designed to help archaeologists differentiate between the two communication systems. Differentiating and documenting these systems fills gaps in an inadequate historical record of their spatial and temporal evolution and contributes to site and survey area interpretations. We find substantial material culture similarities due to shared hardware and the temporal overlap of the introduction of these systems to Colorado. We also identify several material attributes to help differentiate the systems. Accurately identifying cultural resources is a mainstay of archaeological work and we make progress by understanding the possibilities and challenges of differentiating these poorly documented resources.
\end{abstract}

Keywords: telegraph, telephone, material culture, historic, transmission lines

Remnants of historic communication systems, including wooden poles, wires, and insulators, are cultural resources archaeologists may encounter during archaeological site and survey work. Without historical records to identify a system's establishment, construction, or maintenance, the methods for categorizing a communication system as either telephone or telegraph are vague to nonexistent. We confronted this issue as part of a survey team conducting a Class II survey project for the U.S. Forest Service in the Rio Grande National Forest, near Saguache, Colorado. During the survey we encountered a historic site, previously described in a 1975 survey report, that contained numerous temporally diagnostic artifacts and a prominent communication wire and poles. Though the 1975 report authors described these poles, wire, and insulators as a telegraph system associated with a toll road and wagon station, none of the cited documentation supported how they arrived at this conclusion. We conducted documentary research into land ownership records (Bureau of Land Management, General Land Office [BLM, GLO] 2020), historic newspaper archives (Colorado State Library 2020), historic diary entries (Martin 1990), and consulted with local museum personnel. These efforts returned no results regarding land ownership and no record of a communication system in the survey area.

With little to no historic documentation, attempts were made to differentiate the system (also referred to as a "line") using the available material culture: downed and strung wires, rotting wooden poles, and a few glass insulators (figures 1 and 2). These attempts were fruitless as we could not find any publications (archaeological or historical) 


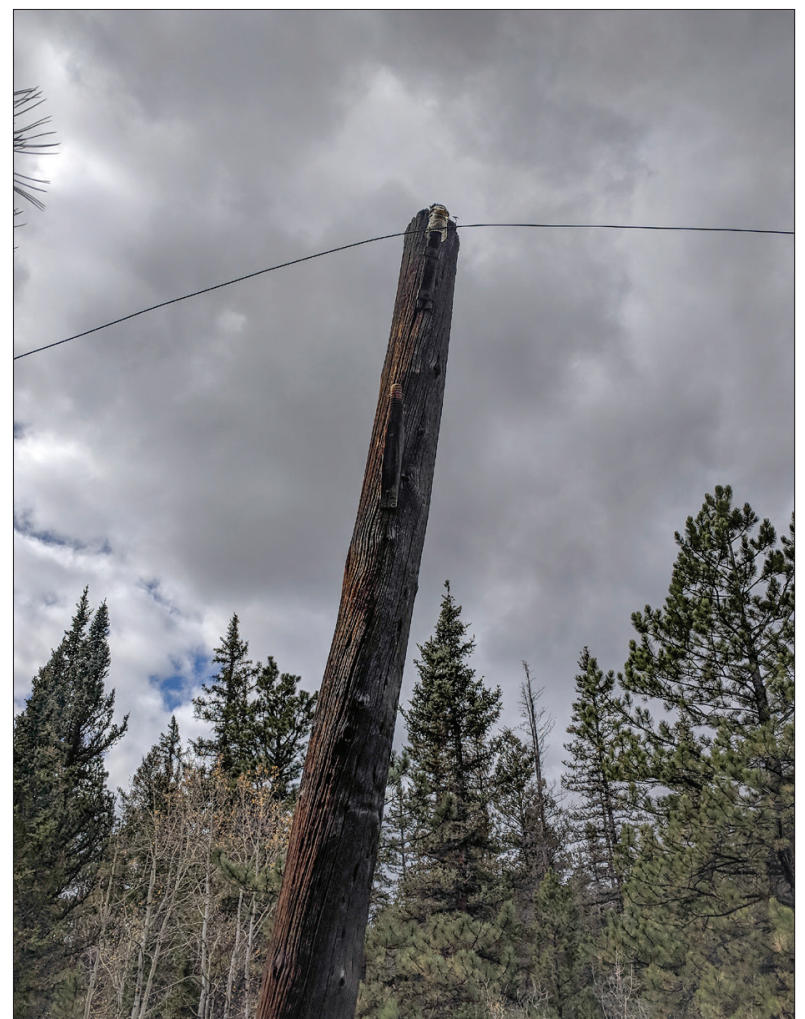

Figure 1. Communication pole associated with the Saguache-area site. Attached at the top of the pole are a glass insulator and iron wire. (Photo by Scott E. Ingram.) that attempted to differentiate the material culture archaeologists might find in the field associated with telegraph and telephone systems. A review of site forms available through Colorado's online cultural resource database, Compass, showed that archaeologists often document the possibility that a system identified by poles, wires, and insulators could be either of the two technologies or a power line. When a distinction was made it was usually through historical documentation or discussions with local historians.

Identifying and differentiating telegraph and telephone material culture is important because it contributes to site and survey area interpretations. The identification of cultural resources, with as much precision as possible, is a mainstay of archaeological work. Whether identifying the contents of historic cans or the former owner of a deteriorated log cabin, determining the interpretive significance of all cultural resources follows their identification. Telegraph and telephone material culture is one type of evidence for identifying human action on a landscape and will verify or compensate for deficiencies of the documentary record. For example, a telegraph line may indicate the former presence of railroad tracks or a military

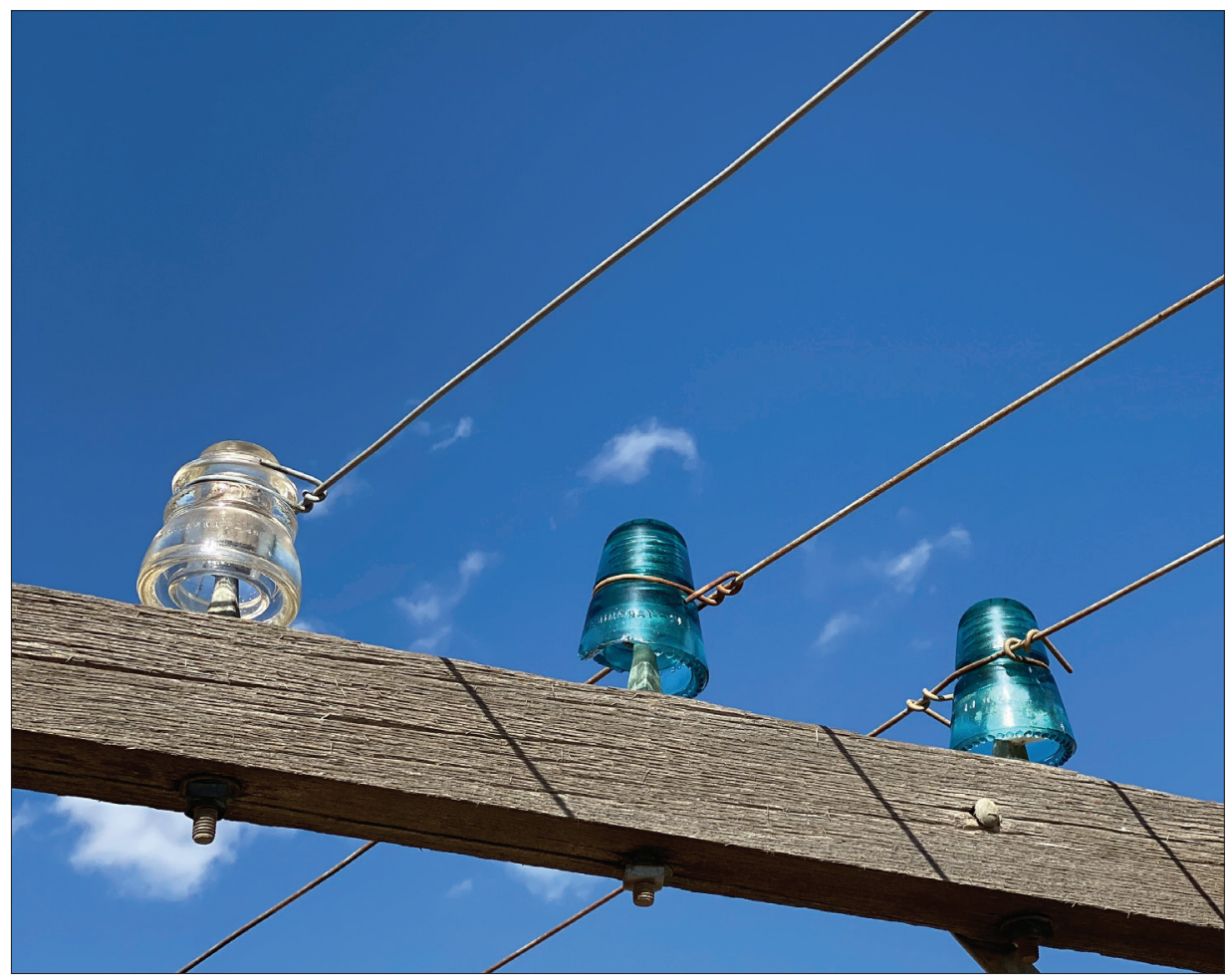

Figure 2. A

communication line crossarm containing multiple insulators and iron wire. (Photo by Joshua Birndorf.) 
base and, according to Vaille (1916), telephone lines may be used as evidence for the presence of a mine, ranch, farm, or even a nearby town. An individual's or town's priorities and economic circumstances can be interpreted by the number of lines present, the materials and methods used to construct them, and their inferred upkeep and maintenance. The telegraph allowed western businesses to communicate product demand and coordinate the transport of goods across the continental U.S. This, in turn, played a significant role in the physical and economic development of the western U.S. (West 2014). The arrival of the telephone was a major event for most cities as a "harbinger of modern civilization" (King 1984:132) and both communication systems proved critical for western settlement (Clark and Corbett 2007:144).

Deficiencies in knowledge of the history and cultural resources associated with the telegraph and telephone in Colorado are identified by Joseph King in the Colorado Engineering Context (1984), developed as an essential resource for archaeologists and other cultural resource managers. King provides a brief and general overview of the early history of both technologies in the U.S. and Colorado and identifies the cultural resource types associated with each. For the telegraph, these types include poles, insulators, wires, relays, generators, sending and receiving apparatus, and stations (King 1984:138). For the telephone, types include exchange buildings (used to connect subscriber lines), telephone offices, public telephone booths, towers, iron and copper wire, cable, timber poles, insulators, switchboards, and telephone instruments (King 1984:131132). King (1984:133) attests to the value of these resources for the communications historic theme by stating, "the enormous strides being made by today's telecommunications industry coupled with the importance attached to better communications by early Coloradans make cultural resources in this theme significant and worth identifying." Data gaps related to the telegraph that are addressed by our study include the need for "representative examples of early telegraph equipment and devices" and identifying a "clearly discernible path used by an early telegraph system" (King 1984:139). Data gaps related to the telephone that our study addresses include the need for "representative examples of early telephone equipment and apparatus" and "representative early telephone structures" (King 1984:133). King (1984:133) highly recommends a historic engineering survey of the state to include resources associated with the communication theme, including the telegraph and telephone. The work presented in this article will be a useful resource if an engineering survey is conducted.

The purpose of this paper is threefold. First, to serve as a guide for archaeologists to interpret and differentiate telegraph and telephone systems based on their poles, wires, and insulators. Though numerous variables confound differentiation, including temporal overlap and similarities between the two technologies, differences between telegraph and telephone lines are often observable through their wires and insulators. Second, to make progress on filling data gaps and answering questions identified in the Colorado Engineering Context (King 1984:133, 139). It is clear the documentary record is lacking and none of the data gaps and research questions are answerable without differentiating between telegraph and telephone material culture when encountered in the field. Building on the Colorado contexts was anticipated by Mitchell (2018) and is one purpose of contributions to Reviews in Colorado Archaeology. Third, this paper is a resource that includes abundant references to multiple primary documents on early telegraph and telephone lines and equipment in Colorado. These will provide archaeologists with a starting point and foundation for site-specific research needs and more comprehensive historical studies in the future. No such resource focused on identifying the material culture of early communication systems exists for archaeologists.

\section{Approach, Methods, and Data}

The theoretical framework and research methods that inform our efforts to differentiate telegraph and telephone material culture are strongly influenced by Michael Schiffer's (2017) strong case approach to behavioral archaeology and interpreting historic artifacts. Schiffer (2017) describes how documentary resources for historic artifacts are often widely dispersed and difficult to obtain (Schiffer 2017:158). He outlines a process for building a strong case for an artifact's life history through examinations of its formation processes and re-use cycles. This process 
often begins by inferring which historic documents may contain information on specific artifacts. Documents can include advertisements, newspaper articles, and various industry records and references (Schiffer 2017). When examining re-use cycles, Schiffer (2017:161) emphasizes the importance of collectors, individuals who have encountered these artifacts on multiple occasions. These individuals, their clubs, and their publications often prove to be essential resources. Through piecing together often obscure and widely dispersed documents, publications, and oral histories a strong case for an artifact's life history can be made.

Consistent with the approach advanced by Schiffer (2017), most of the information utilized in this research was gathered from historic sources, including manuscripts, newspapers, historic archives, patent images, and hobbyist articles and websites. Because the broad outlines of the invention and spread of the telegraph and telephone throughout the U.S. are well documented, we focused on resources describing this process in Colorado and sources that would describe the technological specifics and the physical differences between them.

Two integral sources include Howard T. Vaille's (1916) manuscript entitled History of the Telephone in Colorado, as well as Bill Mahan's (1975) article on the telegraph's entry into the San Luis Valley and James B. Calvert's (2000) history of the telegraph. Other historic documents that mentioned these technologies, including patents, industry supply catalogs, and census records, were also explored. We found these documents at the Colorado College Tutt Library Special Collections and Archives, the Telecommunications History Group archive in Denver (www.telcomhistory.org), and the Denver Public Library. Collectors of glass insulators, artifacts associated with both telephone and telegraph systems, were also interviewed at the $32^{\text {nd }}$ Annual Insulator, Bottle, Barbwire and Collectibles Show held in Albuquerque, New Mexico in 2019. Several interviews were also conducted with Bob Bunker, an avid insulator collector in the San Luis Valley. Collectors provided a wealth of experiential and historical information not available through documentary research. Combining these disparate sources of information allowed for the identification of similarities and differences of telegraph and telephone material culture archaeologists were most likely to encounter in the field.

\section{Development of the Telegraph and Telephone in Colorado}

To understand and differentiate telegraph and telephone technologies within the context of Colorado, a basic knowledge of their development and utilization is necessary. General historical information regarding when telegraph and telephone systems were established in Colorado, where they traveled, and how they were used are an important starting point for identification. If identification is possible, then site and survey area interpretations of their use, spread, and impact can be developed. This section establishes the basic timeline of the development of telegraph and telephone systems in Colorado with some focus on the San Luis Valley, the focus of the survey that prompted this research. Establishing complete histories of the development of each system in Colorado, however, is beyond the scope of this article.

\section{Development of the Telegraph in Colorado}

Colorado completed its first connection to the transcontinental telegraph in 1863, and the first message was sent out of Denver (King 1984:136). Prior to that date, all telegraphic communication to the state was received at a transcontinental station in Julesburg and transmitted to Denver via the Pony Express (Stone 1918:383). Construction of a line from Denver to Pueblo began in 1868 and reached its destination by May of that year (Mahan 1975). As the system spread, stations and headquarters were established in existing buildings and ranches. In July of 1868, the line was extended from Pueblo to Trinidad and, by early fall, it had reached Santa Fe, New Mexico (Mahan 1975:6). In 1872, the Denver \& Rio Grande Railroad Company (D\&RG) gave Western Union, one of the most prominent telegraph companies in the U.S., the rights to commercial telegraph business between Denver and Pueblo (Mahan 1975:6). In 1877, Western Union was granted exclusive rights to telegraph lines along D\&RG's right of way, and the company extended their lines into Alamosa. By 1879, Lake City became one of the first cities in "San Juan country" with 
telegraphic facilities. This connection between Lake City and Del Norte was later extended to Ouray and Silverton (Dolores News, 8 August 1879). A line constructed in 1880 between Kansas City and Pueblo indirectly connected small, south-central Colorado towns, including Alamosa, to the eastern United States (Mahan 1975:7).

Telegraph Types and Quantities

As of 1902, the U.S. utilized four major telegraphic technologies. The 1902 Census of Telephones and Telegraphs describes these technologies and the extent to which they were used throughout the country (Department of Commerce and Labor, Bureau of the Census [DCL, BC] 1902). The single telegraph allowed only one message to be sent over a wire at a time, the duplex was capable of receiving two messages at a time (one in each direction), the quadruplex could send four messages at a time over a single wire (two in each direction), and the machine or automatic telegraph allowed for a message to be keyed faster than it could by hand. In terms of wire mileage, single telegraphs comprised approximately 62.5 percent, quadruplex comprised 22.5 percent, duplex occupied 14 percent, and machine and automatic telegraphs comprised less than 1 percent (DCL, BC 1902:103). Most U.S. commercial telegraph systems ran along the railroad right-of-way (DCL, BC 1902:104). This included 74.2 percent of the nation's telegraph wire mileage (approximately 954,319 miles of single wire). Although railroad companies often employed their own telegraph systems, these were rarely used for anything other than railroad business (DCL, BC 1902:104; Späth 2007:422).

\section{Development of the Telephone in Colorado}

The telephone arrived in Colorado in 1879 and much of its history in the state is described by Howard T. Vaille, a telephone company manager from 1883-1884 (Denver Public Library 2020). Vaille (1916) recorded the history of the Mountain States Telephone Company, a subsidiary of the Bell Telephone Company, for the Colorado Public Utilities Commission. Colorado's first telephone exchange opened February 26, 1879 in Denver (Vaille 1916:2) and according to Stone (1918:386) the Denver exchange "was probably the third or fourth one in the world." A line to Georgetown was the first long distance line built in Colorado (Stone 1918:387). Later that year, during the mining boom, another exchange was opened in Gunnison, though this closed a few years later after the mining excitement dwindled. The establishment of telephone exchanges or lines in the wake of mining success was a common occurrence throughout Colorado (King 1984:130). In 1881, a line was established between Lake City and Silverton via the Animas Forks Valley (Silver World, 2 July 1881; Jon Horn, personal communication 2020). The telephone continued to grow in popularity, and by 1883 customers included hotels, livery stables, drug stores, and undertakers. It was also common for a prominent doctor or lawyer to have a direct line to their residence (Vaille 1916:24). Cattlemen were some of the first to adopt the telephone as soon as it was available, often establishing connections between their homes, their ranches, other ranches, and railroad shipping points (Vaille 1916:98). In 1884, a line was extended from Denver to Pueblo (Vaille 1916:33) and by 1886 an exchange opened in Cañon City (Vaille 1916:39).

Telephone lines continued to spread throughout 1889, when they passed through Trinidad to New Mexico and branched into the San Luis Valley, Salida, Holly, Buena Vista, and Cripple Creek (Vaille 1916:48). By 1895, San Luis Valley residents had established multiple independent telephone companies (Vaille 1916:48). These smaller companies were later purchased by Bell in 1902, and the lines were updated with newer technology (Vaille 1916:87). Connections began extending over mountain ranges, into mining camps and, in some cases, into the mines themselves. By 1899, exchanges had extended to Breckenridge, Ordway, Sterling, Delta, Ouray, Fort Morgan, and Las Animas. A map of Colorado telephone lines as of approximately 1909 is provided in figure 3. (See supplement A for a complete map of Bell Telephone Companies lines in the U.S.)

\section{Telephone Types and Quantities}

The U.S. government categorized telephone systems into three types as of 1902: commercial systems, mutual systems, and independent farmer/rural 
lines (DCL, BC 1902). Commercial systems were generally operated by firms or individuals for the sole purpose of profit. Both the Bell Telephone Company and its subsidiary Mountain States Telephone Company fell under this category. Mutual systems were generally established by multiple people within a community. Unlike commercial systems, the establishment of mutual systems was not motivated by profit but rather by people in a community who believed they could benefit from telephonic connection. Rural/farmer lines were defined based on the absence of a central office or telephone exchange. Although these lines were often connected to a mutual or commercial system, they generally connected farmhouses and ranches. Some even used the barbed wire in their fences to transmit telephone signals (DCL, BC 1902:6). Independent telephony (the operation and maintenance of telephone lines) in Colorado significantly grew in popularity from 1894-1907 in response to the expiration of Bell's telephone patents (King 1984:131). Prior to 1906, all American telephone apparatus were rented (Vaille 1916:39).

Telephone systems grew significantly in Colorado after their introduction in 1879, although official data collection regarding this growth did not begin until the 1902 Census of Electrical Industries (DCL, BC 1902). This census and its revision,

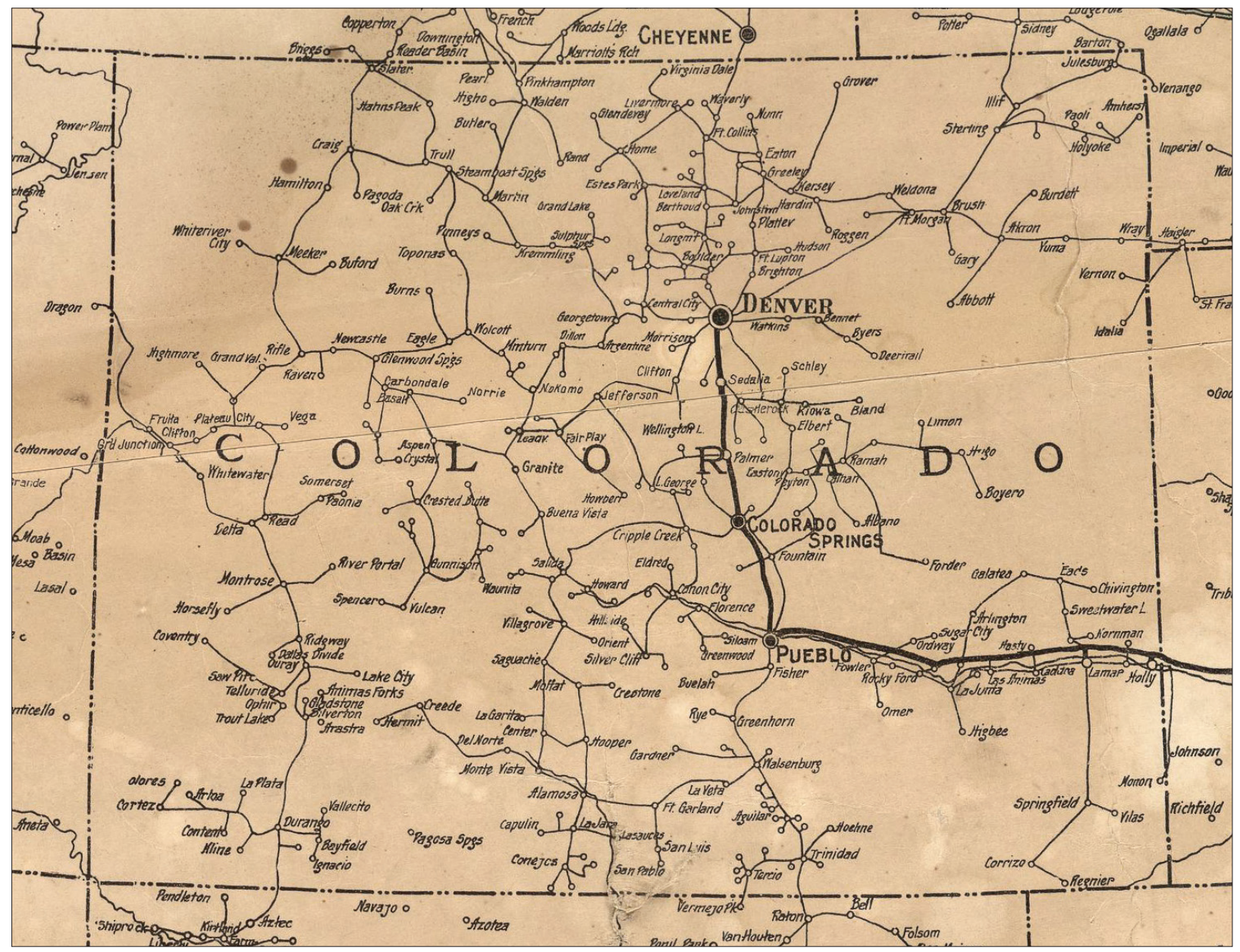

Figure 3. Map of American Bell Telephone and Telegraph Co. local and long-distance lines in Colorado (American Telephone and Telegraph Company 1910). Knowledge of where telephone lines ran can assist archaeologists in determining whether what they encounter is a telephone or a telegraph line, as well as indicate where undocumented telephone lines may be encountered. This map is a useful resource for archaeologists and is accessible at the David Rumsey Map Collection, David Rumsey Map Center, Stanford Libraries (www.davidrumsey.com). Supplement $A$ is a complete version of the map. 
conducted in 1922 (Department of the Bureau of the Census [BC] 1922), contain information and statistics regarding the number and extent of Colorado's telephone systems. In 1902, there were a total of 40 recorded rural telephone systems (DCL, BC 1902:34). Of these, 37 were commercial systems with approximately 261 miles of wire and 3 were mutual systems with approximately 70 miles of wire (DCL, BC 1902:34). At the time of this census, there were no independent rural/farmer lines recorded in Colorado (DCL, BC 1902:34). By 1922, however, the census stopped differentiating between the three previously established line categorizations. Although the 1922 census of telephones identifies a large number of farmer lines, the lack of both explicit ownership and, often, a definite name to associate with the line made them difficult to document. The 1922 census states that recording in such detail would have been impossible without "undue expenditure of time and money" (BC 1922:31). Thus, developmental comparisons can only be drawn through total wire mileage and the number of existing lines. In 1907, Colorado had a total of 104 telephone systems with 173,638 miles of wire (BC 1922:11-12). By 1922, the number of systems increased to 841 with approximately 412,816 miles of wire (BC 1922:11-12). The growth of the Colorado telephone system in terms of wire mileage and system count is presented in figure 4 . As the 1902 census contained conflicting information regarding the number of telephone systems and total miles of wire in 1902, values for that year are not included in figure 4 (DCL, BC 1902).

Confounding Similarities Between the Telegraph and Telephone

The nearly sixteen year gap between entry of the telegraph and telephone into Colorado (1863 vs. 1879), as well as the seemingly large leap forward in technical practicality of the telephone, have the potential to promote a few misconceptions: namely that the telephone and telegraph industries were inherently different and that the telephone replaced the telegraph. Neither of these were the case (Späth 2007:422). The 1902 Census of Telephones and Telegraphs (DCL, BC 1902:3) states that "in terms of technique and engineering, the relation of telephony and telegraphy is one of the most intimate nature." Späth (2007:422) corroborates this statement, arguing that telegraph and local telephone lines used similar technologies. Engineering was not the only similarity: "A.G. Hood, manager of the Western Union Telegraph Company, was also manager for
Figure 4. Graph showing the growth of the Colorado telephone network in terms of miles of wire and number of systems (BC 1922:11-12).

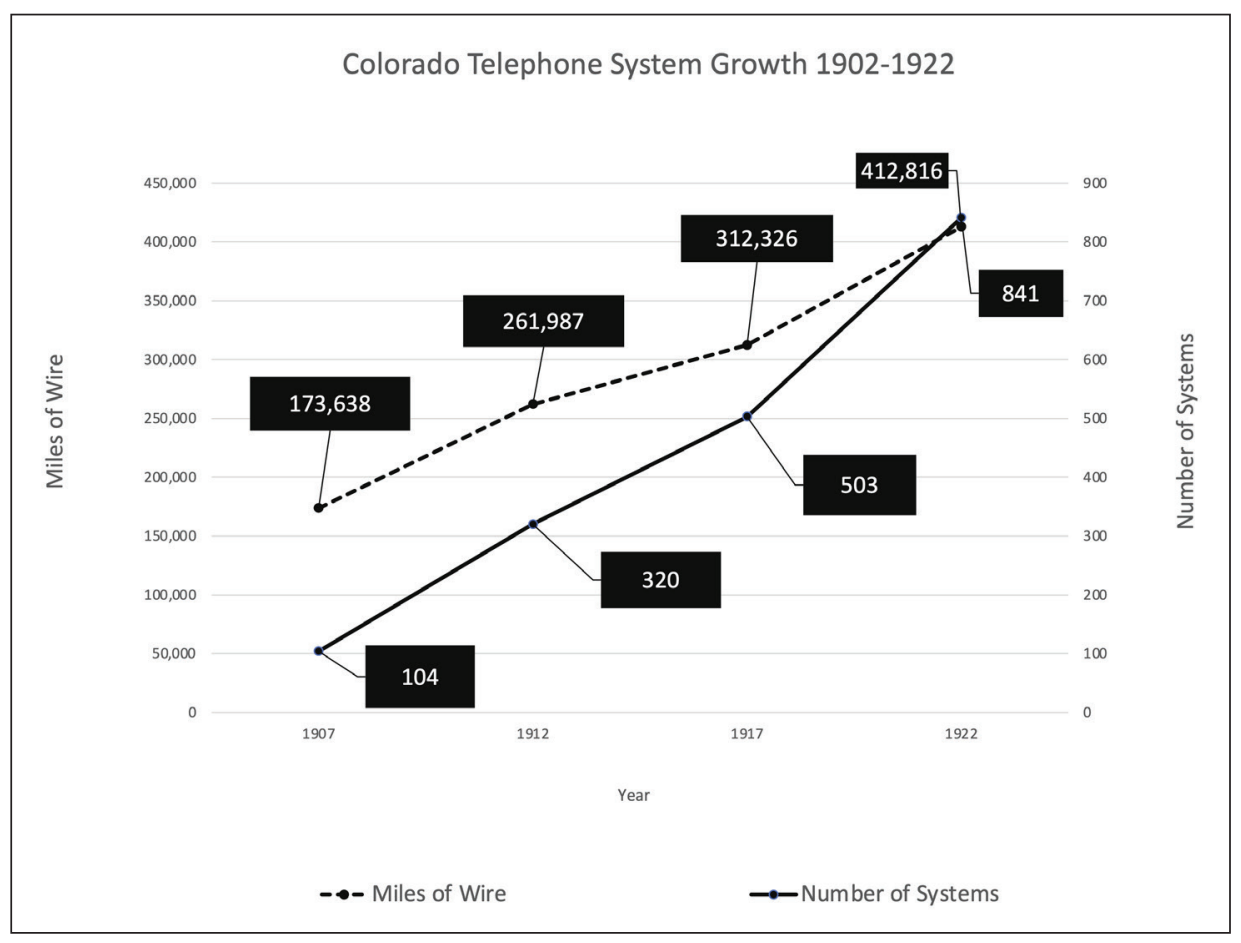


the telephone company" during the early years in Leadville (Stone 1918:387).

Both systems involved transmitting an electrical signalacross a wire for the purpose of communication (Library of Congress [LOC] 2020). In constructing lines, early telephone companies closely followed many telegraph companies practices, though specifics regarding these practices were not addressed (DCL, BC 1902:40). This suggests that the two technologies' material culture are relatively similar, an inference corroborated by several collectors of glass insulators and artifacts associated with both telegraph and telephone lines. According to two insulator collectors, the construction of a new telephone line was an expensive venture and those that undertook such a venture often used salvaged materials. The inherent similarities between the two technologies complicates the process of material culture-based differentiation.

The telephone was, in many ways, a significant improvement over the telegraph. Unlike the telegraph, which required a skilled operator, the telephone was accessible to nearly anyone capable of speech (Saguache Chronicle, 16 February 1878). Despite its advantages, the telephone did not replace the telegraph. Through research into Colorado's historic newspaper database (Colorado State Library 2020), it is clear that the technologies operated side-by-side from the telephone's entry into the state to, at the very least, the 1930s. Based on a keyword search in the Colorado Historic Newspapers Collection (Colorado State Library 2020), mentions of the telegraph become less common as time progresses.

The telegraph's persistence in Colorado may be attributed to the few but notable advantages it had over the telephone, the first of which was price. Telegraph systems were cheaper to build and operate than telephone systems. They often required half the wire, could take advantage of cheaper materials, and did not require the same careful maintenance of a telephone line (Vaille 1916:35). Although the telegraph and telephone offered similar short and medium-distance rates, the lower costs associated with telegraph-line production allowed long distance messages to be sent at much cheaper rates (Vaille 1916:35). These structural and monetary advantages were likely not the only factors promoting the continued use of the telegraph. Much like the quadruplex and duplex telegraph systems that could manage simultaneous messages, the technological advantages of the telephone were not sufficient to overcome a preestablished telegraph infrastructure. Duplex and quadruplex telegraph systems comprised only 36.5 percent (DCL, BC 1902:104) of total U.S. wire mileage as of 1902.

\section{Summary}

The sixteen-year difference in the arrival of telegraph (1863) and telephone (1879) systems in Colorado provides a narrow window to differentiate the systems by association with dated structures or events. Knowing when and where each system developed and spread would be most helpful for differentiating the systems, but there is no systematic or comprehensive source that documents the spatial evolution of either system across the state (but see Vaille 1916, Stone 1918:383-391, and Hackenburg 1986 for useful narratives). In general, the telegraph entered Colorado in Denver in 1863 and by 1868 a line was established to Pueblo, Trinidad, and Santa Fe (Mahan 1975). In 1877, the Denver \& Rio Grande Railway Company gave Western Union the rights to commercial telegraph lines along railways in southern Colorado and a line was established in Lake City by 1879 . The telephone entered Colorado in 1879 in Denver and local telephones systems associated with mining began that year in Gunnison (Vaille 1916) and Leadville (Stone 1918:387). We have not attempted to reconstruct the full development of either system; there is more to the story and archaeologists will need to build this story from the ground up. Documenting the spatial pattern of growth of both systems across the state will be an important contribution for future archaeologists or historians.

\section{Differentiating Telephone and Telegraph Material Culture}

Differentiating telegraph and telephone systems in the absence of historic records requires building an interpretation of system type informed by the three primary components of material culture associated with communication systems: wires, poles, and insulators. 
Wires

The production and improvement of the wires and cables results in three potentially diagnostic attributes: material, organization, and gauge (diameter).

\section{Material}

Iron and galvanized iron wires (figure 5) were exclusively used for telegraph and telephone lines until the invention of hard-drawn copper wire in 1877 (Copper Development Association [CDA] 2020). The new copper wire production process, invented by Thomas B. Doolittle, involved drawing a copper rod "cold through a series of dyes" (Rhodes 1929:91). This created a wire with higher conductivity than the iron in prior use (McQuarrie 1911:511) and much higher tensile strength than the copper employed on lines outside of Colorado in the mid-1800s (Rhodes 1929:91). These advantages were put to various tests throughout the 1880s (Rhodes 1929:91), and hard drawn copper wire's application to telephone and telegraph lines in Colorado increased throughout the 1890s (King

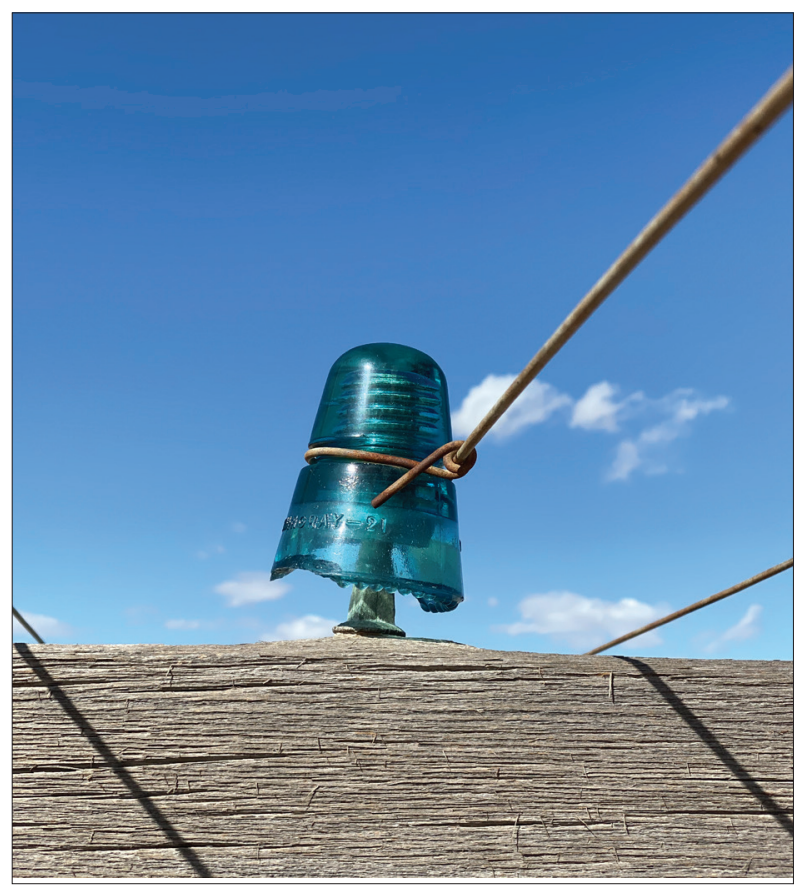

Figure 5. A strand of iron wire attached to a glass insulator on a communication line. (Photo by Joshua Birndorf.)
1984:138). It is unlikely, however, that copper quickly and completely replaced iron because copper was significantly more expensive than iron and construction costs were higher because the lower tensile strength of copper required shorter spans (Stone 1918:389). Despite copper's advantages, iron was still a perfectly functional material for many existing communication systems. Thus, it is reasonable to assume that existing iron lines were not immediately replaced, and that iron was likely still used in the construction of new lines as a cost-cutting measure.

\section{Organization}

Wire organization refers to two attributes: whether the wires are packaged within a cable and, if so, how, and the position of the wires on a pole or crossarm (the horizontal piece of wood to which pins, insulators, and wires were secured). How the wires are organized can provide a terminus post quem, or earliest possible date of production, and can differentiate between the two communication technologies. Both telegraph and early telephone lines ran on a grounded circuit: a system that required only one wire. Grounded circuits, however, had a significant problem. When placed on a crossarm next to other communication wires, they were subject to interference (CDA 2020). Hackenburg (1986:23) describes this interference as "screeches, squawks, and all sorts of other uncanny noises." He also describes the issue of crosstalk, a phenomenon in which an individual using a telephone could hear the conversation travelling along a neighboring line (Hackenburg 1896:23). To solve this issue, Alexander Graham Bell patented his metallic circuit in 1879 and revised it for use with telephone cables in 1881 (Bell 1879, 1881). In his patent description, Bell states that this method involved stringing two wires instead of one: a direct wire and a return wire. The direct wire served to transmit the telephone signal, whereas the return wire was used to cancel out interference. To cancel out interference, the direct and return wires must be equidistant, or relatively so, from the disturbing wire (the other communication wire causing interference). A similar effect could be achieved using the twisted pair method, in which the direct and return wires were twisted around each other. 
In doing so, equidistance of the two wires from the disturbing wire was ensured (Bell 1879:2), as shown in figure 6 .

Much like hard-drawn copper wire, implementing the metallic circuit was an expensive and difficult endeavor as it required twice the wire of a grounded circuit (CDA 2020). Thus, although the technology arrived in Denver, Colorado in 1893, grounded circuits continued to be utilized (Vaille 1916:63). As of 1902, independent rural/farmer lines still employed grounded circuit technology (DCL, BC 1902:6). Even so, as Bell's patents describe this two wire system as an "improvement in telephone circuits," and lack any mention of implementation on telegraph lines, the presence of equidistant wires or a twisted pair can indicate that a transmission line was associated with a telephone system with an earliest production date of 1879 (Bell 1879).

Wires and communication systems, however, were not exclusively organized separately on a crossarm. As communication systems increased in popularity, communication poles became overcrowded with wires. The solution was to consolidate and organize the wires into a cable (CDA 2020). The 1882 Western Electric Company's catalog for Bell Telephone Company describes the anatomy of both telephone and telegraph cables. They contained twisted pairs of conductors (wires) inside a lead tube. The conductors were insulated from one another using paraffin wax, gutta percha (a tough, tree based, plastic substance), or rubber (CDA 2020; Western Electric Company [WEC] 1882:15) (figures 7 and 8). For structural support, a long spiral of either No. 4 or No. 6 iron wire was wrapped around the cable. An additional spiral of No. 12 iron wire could be added for extra protection (figure 9).

The number of conductors in a cable may be an indicator of a telephone or telegraph system. An ad for Patterson telephone and telegraph cables suggests that telephone cables may contain up to 75 conductors while a telegraph cable may contain from 1 to 20 conductors (WEC 1882:15). Though these figures may not apply to all manufacturers, it's possible that a cable containing more than 20 conductors, or the twisted pairs associated with Bell's metallic circuit is associated with a telephone system (Bell 1881:2; WEC 1882:15). Because both telephone and telegraph systems employed cables, their exteriors cannot be differentiated. Thus, a dormant cable cross section can be inspected to determine the number of conductors and their arrangement.

\section{Wire Gauge}

The gauge (diameter) of a wire cannot be used to differentiate communication system types but it

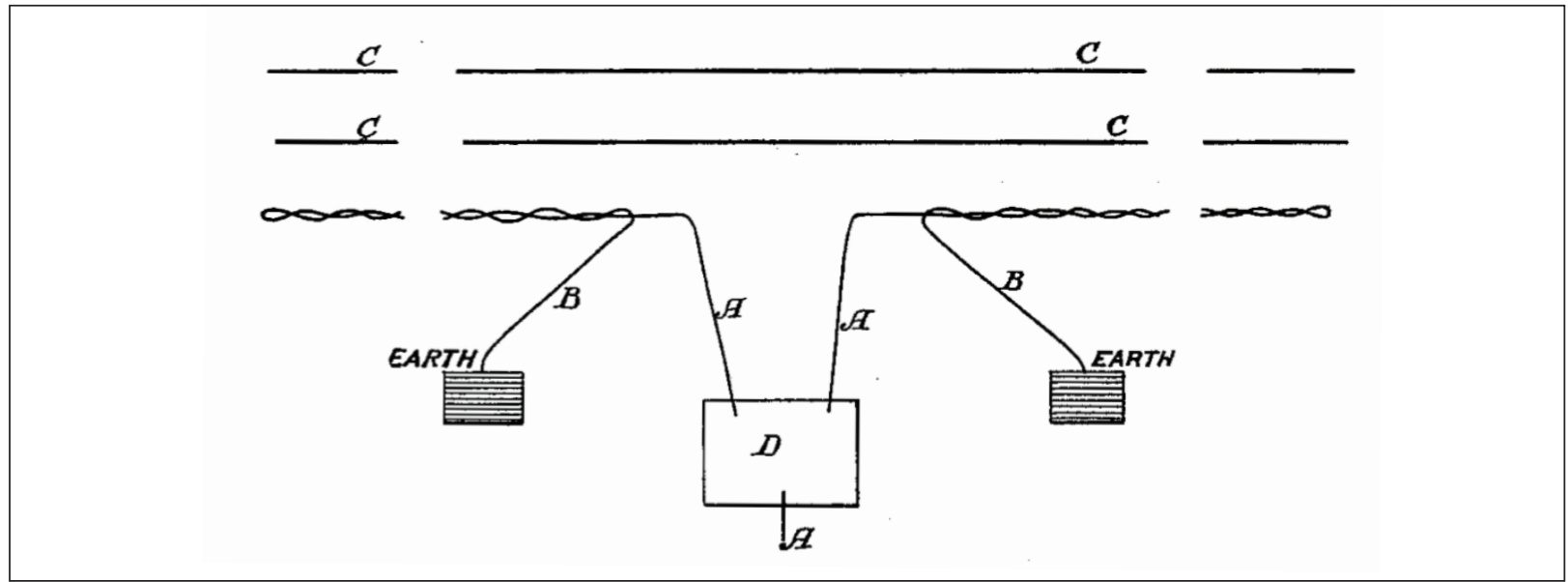

Figure 6. A metallic telephone circuit diagram from Alexander Graham Bell's original patent. Lines labeled " $C$ " represent disturbing wires, lines labeled " $A$ " represent direct wires, and lines labeled " $B$ " represent return wires. Wires " $A$ " and " $B$ " are kept equidistant from disturbing wires " $C$ " by twisting them around one another. Line " $B$ " returns to the earth whereas line "A" travels to the telephone apparatus. Item " $D$ " represents the central telephone office (Bell 1879). 


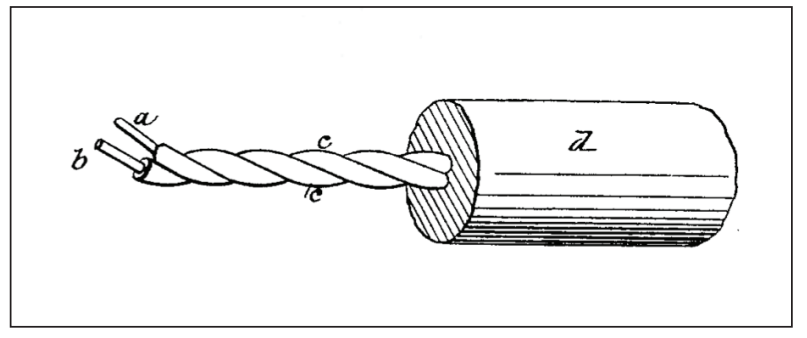

Figure 7: A twisted pair metallic circuit from Alexander Graham Bell's original patent. " $A$ " and " $B$ " represent individual conductors. " $C$ " is the wires' protective coating of silk or cotton soaked in paraffine wax. "D" represents gutta pecha, tarred rope, or other insulating materials (Bell 1881).

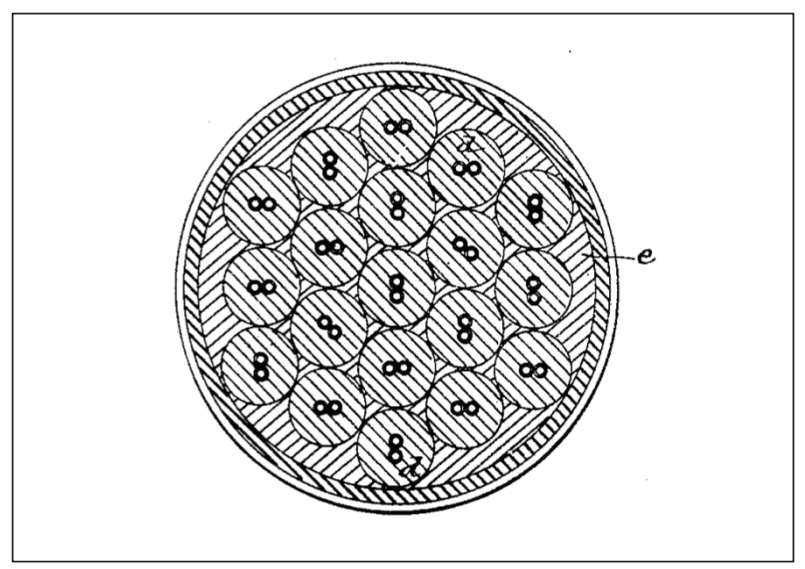

Figure 8. A cross section of Alexander Graham Bell's "improved" telephone cable representing individual twisted pairs of conductors and their surrounding insulating materials (Bell 1881).

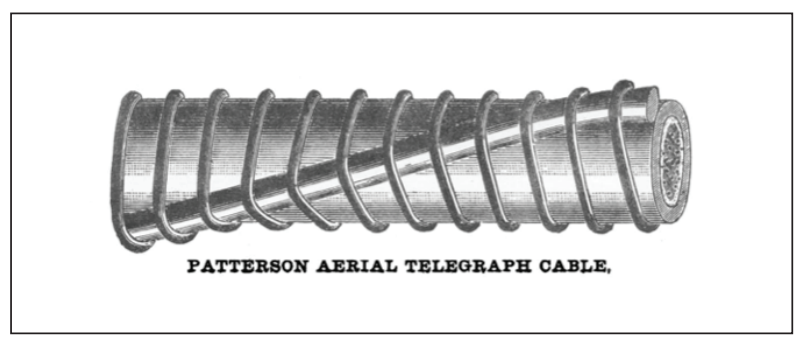

Figure 9. A depiction of Patterson Aerial Telegraph Cable from a 1882 Western Electric Company supply catalog. The larger strand of support wire coiled around it is either No. 4 or No. 6 AWG iron wire. Additional support is provided by the thinner, more frequent coils of No. 12 AWG iron wire (WEC 1882:14). Both strands prevented kinking while retaining the cable's flexibility (Jon Horn, personal communication 2020). can indicate a line's intended length. Identifying the length of a transmission system, especially when only a small portion of the system remains, can help determine the type of system (e.g., a small mutual or rural group vs. a larger commercial system). The first wire gauge system in the U.S. was called the Birmingham Wire Gauge (BWG) (Calvert 2000). This gauge, however, lacked uniformity, as different manufacturers had different ideas as to which gauge numbers corresponded to which wire diameters. American Wire Gauge (AWG), also known as Brown and Sharpe Gauge (B\&S) was developed to fix this issue in 1857 (Calvert 2000), though it did not replace BWG, as that measurement standard still existed within the 1907 Western Electric Catalog of Telephone Apparatus and Supplies (WEC 1907:118). According to the 1902 Census of Telephones and Telegraphs (DCL, BC 1902:41), short telephone lines generally used No. 12 AWG wires, whereas long-distance or toll lines used either No. 8 or No. 6 AWG wires (table 1). Telephone lines designed to travel farther, in general, used thicker wires. This generalization should be utilized with caution, however, as it operates under the assumption that the line was built with a pre-determined purpose and destination and utilized new materials rather than recycled ones. Although not applicable in Colorado, as the advent of American Wire Gauge took place six years before the telegraph's entry into the state (King 1984:136), it can contain temporally diagnostic information. Wires with diameters more closely associated with AWG than BWG may point to 1857 as their earliest possible date of production (Calvert 2000).

Insulators

Where there are historic communication lines, there may also be glass insulators (figure 10). Porcelain insulators were also utilized in the U.S., though these were generally employed on higher voltage power lines due to their superior protective properties (Collectors Weekly 2020).

For telegraph and telephone systems, insulators affixed the wires to the poles and served as an intermediary, non-conductive material to solve the problem of leakage, or escaping electrical current from the line to the ground below (Calvert 2000). This leakage was amplified as soon as the insulators 
Table 1. American Wire Gauge (AWG) and Birmingham Wire Gauge (BWG) numbers and their associated diameters (WEC 1907:150).

\begin{tabular}{lll}
\hline & \multicolumn{2}{c}{ Diameter $(\mathrm{cm})$} \\
\cline { 2 - 3 } Gauge No. & AWG & BWG \\
\hline 1 & 0.735 & 0.762 \\
2 & 0.654 & 0.721 \\
3 & 0.583 & 0.658 \\
4 & 0.519 & 0.605 \\
5 & 0.462 & 0.559 \\
6 & 0.412 & 0.516 \\
7 & 0.366 & 0.457 \\
8 & 0.326 & 0.419 \\
9 & 0.291 & 0.376 \\
10 & 0.259 & 0.340 \\
11 & 0.230 & 0.305 \\
12 & 0.205 & 0.277 \\
13 & 0.183 & 0.241 \\
14 & 0.163 & 0.211 \\
15 & 0.145 & 0.183 \\
16 & 0.129 & 0.165 \\
17 & 0.115 & 0.147 \\
18 & 0.102 & 0.124 \\
19 & 0.091 & 0.107 \\
\hline
\end{tabular}

became dirty or wet. Thus, many changes throughout the course of their development were to increase water runoff. These improvements and other changes are traceable through their patents, making some insulators temporally diagnostic artifacts. The most common insulator manufacturers in the U.S. Southwest were Brookfield and Hemingray, according to collectors queried. Insulator collector websites contain a wealth of information that can be used to identify an insulator, its use, and dates of manufacturer (e.g., www.insulators.info and https:// allinsulators.com/).

Insulator threads, patented in 1865 by Luis Cauvet (1865), are the first temporally diagnostic improvement to the glass insulator (Cleland 1983:6; Milholland and Milholland 1973:1; Miller et al. 2000:15). Prior to this innovation, insulators were attached to wooden or metal pins using friction, often with the addition of burlap, tar, or other securing materials (NIA 2020). Threads allowed insulators to screw onto and fix themselves more securely to the pins (figure 11) (Cauvet 1865). Cauvet's process involved placing molten glass into an insulator mold, transferring the mold to a lever press to form the hole, and, finally, before the glass

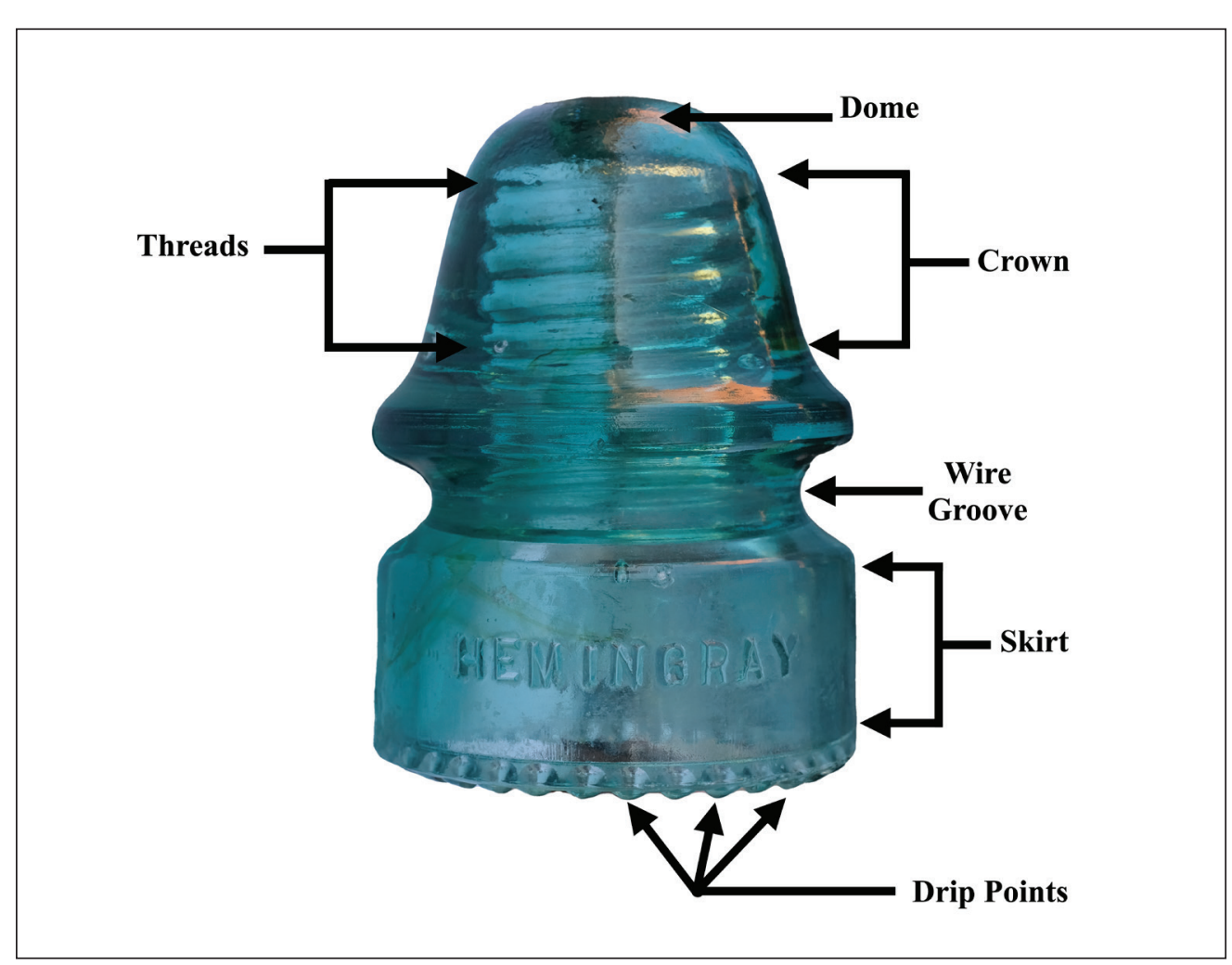

Figure 10. A glass insulator with labeled anatomy and identifying characteristics. Adapted from Meier (2009). (Photo by Joshua Birndorf.) 
set, placing the mold under a slow screw press to form the interior threads (Cauvet 1865). Homer Brooks improved upon this process in 1870 with his patent for a glass insulator press that could insert threads more efficiently than Cauvet's mold (Brooks 1870; Milholland and Milholland 1973:11). Brookfield and Hemingray followed suit in April and December of 1871, respectively (Brookfield 1871; Hemingray 1871). Insulators without threads, then, are earlier than those with threads and more likely associated with telegraph than telephone systems, as improved threading technology existed well before the telephone's entry into Colorado (Vaille 1916).

Another diagnostic addition to insulators came about in 1893 with the addition of drip points or, as inventor Ralph G. Hemingray (1893) called them, "teats" (figures 10 and 12). Drip points were added to attract and remove droplets of water running down the side of an insulator (Hemingray 1893; Milholland and Milholland 1973:12). The patent date for drip points, May 2, 1893, made its appearance on Hemingray insulators that year and continued throughout the early 1900s (Hemingray 1893; Willis 2019).

Temporal information can also be gathered from insulator embossing patterns; specifically, on various iterations of Hemingray insulators. On his website (https://hemingray.info/), insulator collector and

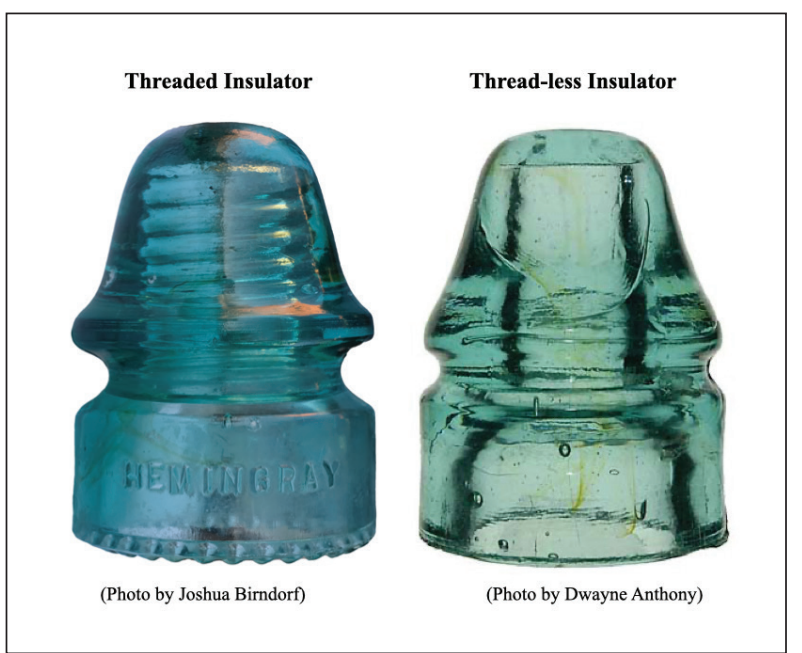

Figure 11. Non-threaded vs. threaded insulators. The insulator on the right has no threading. The insulator on the left has threading clearly visible through the crown (NIA 2020).
National Insulator Association director Christian E. Willis summarizes how these patterns changed throughout Hemingray's development. Of these, the easiest features to identify include patent dates and the display of the company name. Insulators with "Pat. Dec. 1871" embossed on either the front of the skirt or crown were produced between 1871 and 1887 (figure 12). The date identifies Robert Hemingray's patent for "improvement in molding telegraph-insulators" (Hemingray 1871). The company embossed insulators with "H.G.CO." from 1887 to 1898 and the "Hemingray" name (figure 13) began to appear on their insulators in 1895 and continued through the 1900s (Willis 2019). With photo documentation of insulators in the field, collector websites and catalogs can be searched for more specific information, including the patent dates which establish "no sooner than" dates.

Telephone insulators may be relatively smaller than telegraph insulators. Although a systematic, comparative study of known telegraph and telephone insulators would be necessary to verify this claim, six insulator collectors, many of whom have climbed poles and collected these artifacts for decades, were questioned as to whether or not a difference between telegraph and telephone insulators existed. Multiple collectors claim that telephone insulators are, in general, smaller than telegraph insulators (e.g., Bob Bunker, personal communication 2019). Bunker claimed this was a matter of perceived quality: early insulator manufacturers believed heavier glass to be of higher quality and, therefore, more effective for insulation. However, this belief later proved to be incorrect (Bob Bunker, personal communication 2019). A reduction in size and weight may have also been advantageous for expanding lines into more remote areas (McDougald and McDougald 2013:6). Insulator collector of 31 years Bill Meier created a table that identifies common insulator styles and their associated uses. These styles, also known as Consolidated Designs (CDs), are classified by number (Meier 2009; Milholland and Milholland 1973). Table 2 is an adapted version of Meier's table. Many of the insulator collectors' statements were corroborated by Meier's insulator profiles. Most collectors identified telephone insulators as lighter than telegraph insulators. Even so, weight and shape alone should be not be used as indicators. For a 


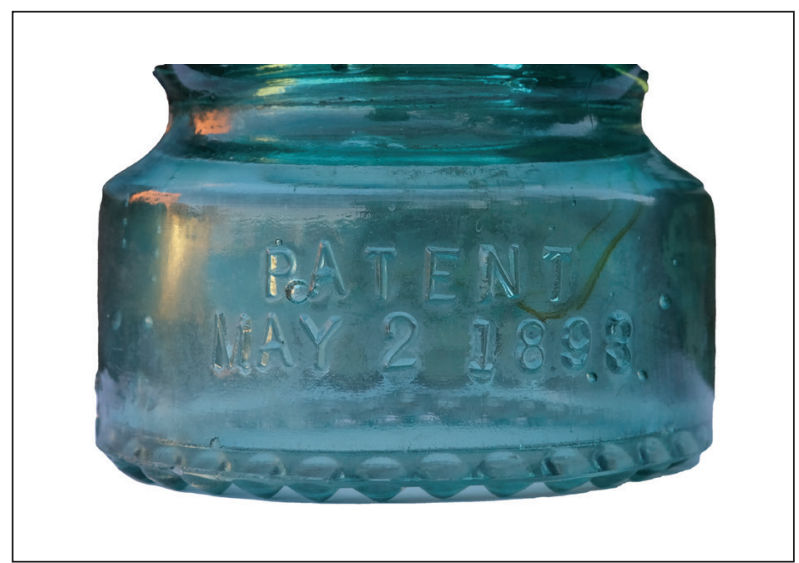

Figure 12. The patent date for drip points (May 2, 1898) embossed on the skirt of an insulator. (Photo by Joshua Birndorf.)

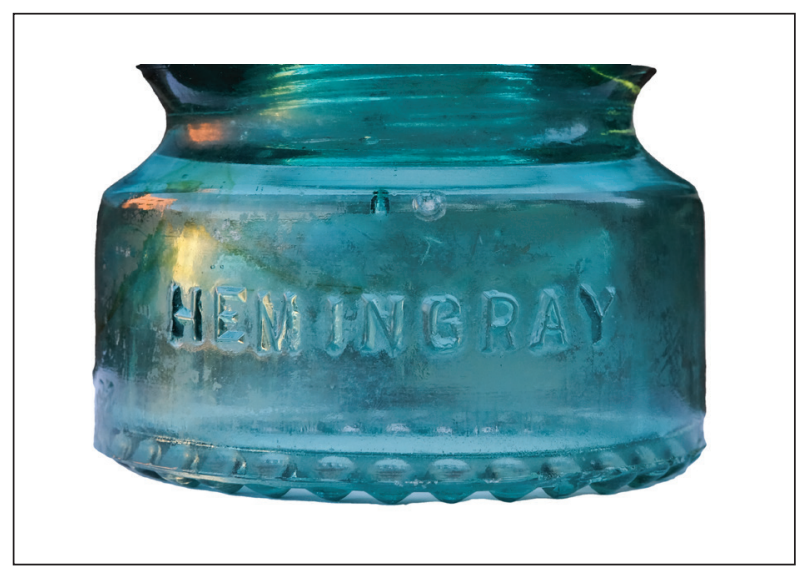

Figure 13. An insulator with the brand "Hemingray" embossed on the skirt. (Photo by Joshua Birndorf.)

strong differentiation argument, multiple methods should be used.

Though Hemingray and Brookfield are cited as representative examples of insulators used in the U.S. Southwest, one smaller manufacturer is also of significant interest. The Valverde Glass Works produced insulators in Valverde, Colorado (located 2 miles south of Denver) and distributed them throughout the state (McDougald and McDougald 2013: 96). Although the factory changed names multiple times, it was commonly referred to as Valverde Glass Works throughout its period of glassware production (McDougald and McDougald 2013; Lockhart et al. 2015:65). In 1895, Robert Good Jr. rented and re-opened the defunct glass factory, and renamed it Denver
Flint Glass Company in 1897 (McDougald and McDougald 2013: 96). Insulator production briefly ceased in June of 1899, as a fire severely damaged the plant (McDougald and McDougald 2013:97; The Colorado Daily Chieftain, 28 June 1899). Between 1895 and 1899, insulators produced at the Valverde plant were embossed "R. Good Jr." on the front skirt, and "Petticoat" on the back. Towards the end of this period, insulators were embossed with "Denver COLO." below Good's name on the front skirt (McDougald and McDougald 2013:96). The plant re-opened under new ownership in October of 1899 and was re-named the Western Flint Glass Company (McDougald and McDougald 2013:97). The name was again changed to Western Glass Manufacturing Company in November of 1900, as a Western Flint Glass Company already existed in Eaton, Indiana (Lockhart et al. 2015:67). Insulators produced between October of 1899 and November of 1900 were embossed "W.F.G. CO." above "Denver, CO.” (McDougald and McDougald 2013:97; Hill 1968:74). The factory operated under the Western Glass name until its closure between 1909 and 1910 and throughout this period embossed their insulators with "W.G.M. CO." (Hill 1968:13; McDougald and McDougald 2013:98).

Valverde plant insulators were used widely throughout Colorado and were used to a lesser extent in neighboring states. The precise extent of their utilization, however, is not entirely clear. Bob Bunker (personal communication 2020) states that these insulators likely found use in small local or rural telephone lines, as buying from an in-state producer was less expensive. This interpretation is corroborated by the fact that Valverde Plant insulators were of generally poor quality. They were frequently under and over poured into their molds, which resulted in distortion and inconsistent coloration (Lockhart et al. 2015:67; McDougald and McDougald 2013:98). Miller and Katonak (2005), however, describe a much more varied utilization, citing usage for railroad telegraph lines, rural telephone lines, telephone toll lines, and even low voltage power lines.

In summary, although glass insulators can contain temporally diagnostic information it is difficult to use these artifacts to distinguish between a telephone and telegraph system because both systems relied on similar wire technologies. 
Table 2. Common insulator designs, their associated dimensions, and common uses.

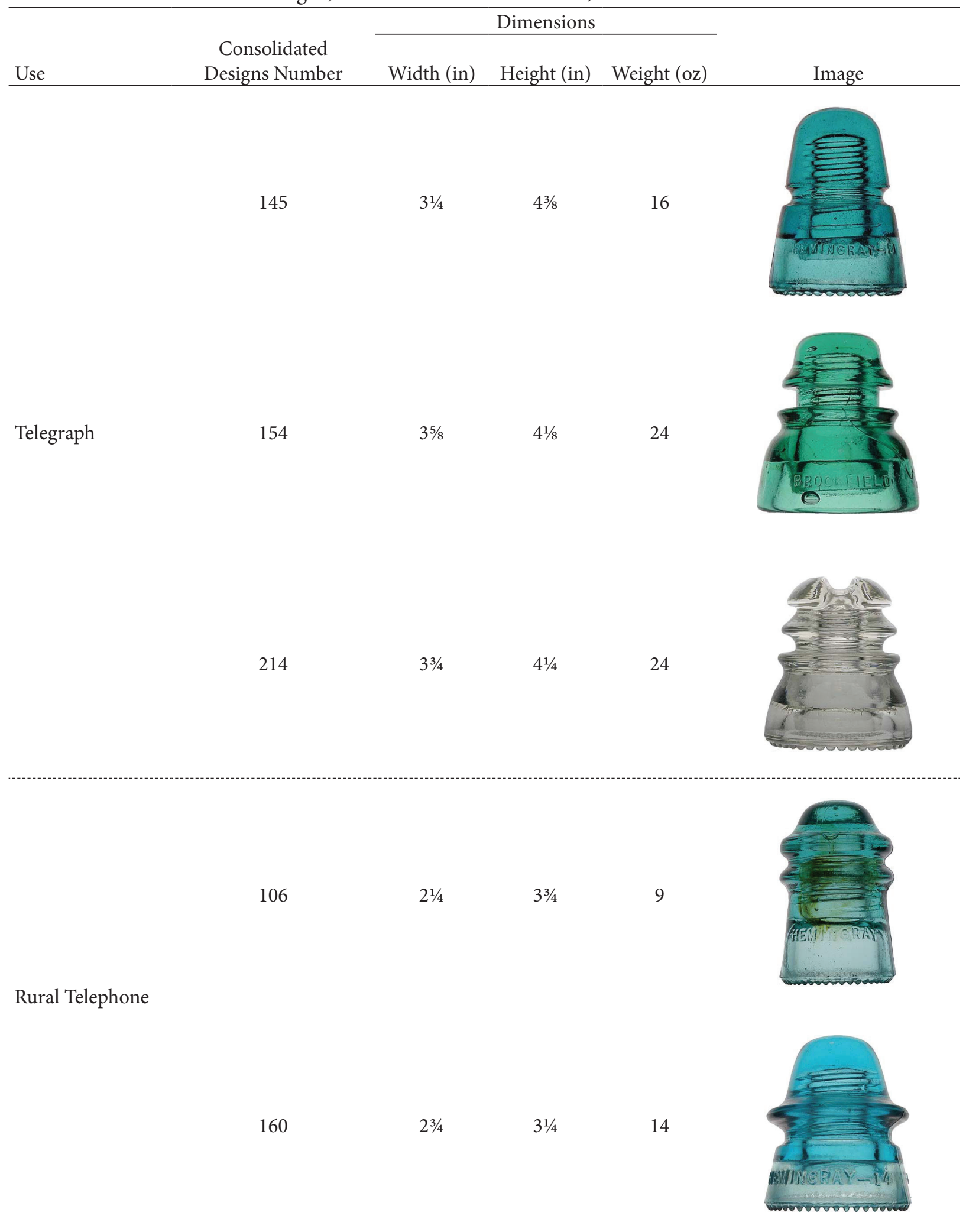


Table 2. Common insulator designs (continued).

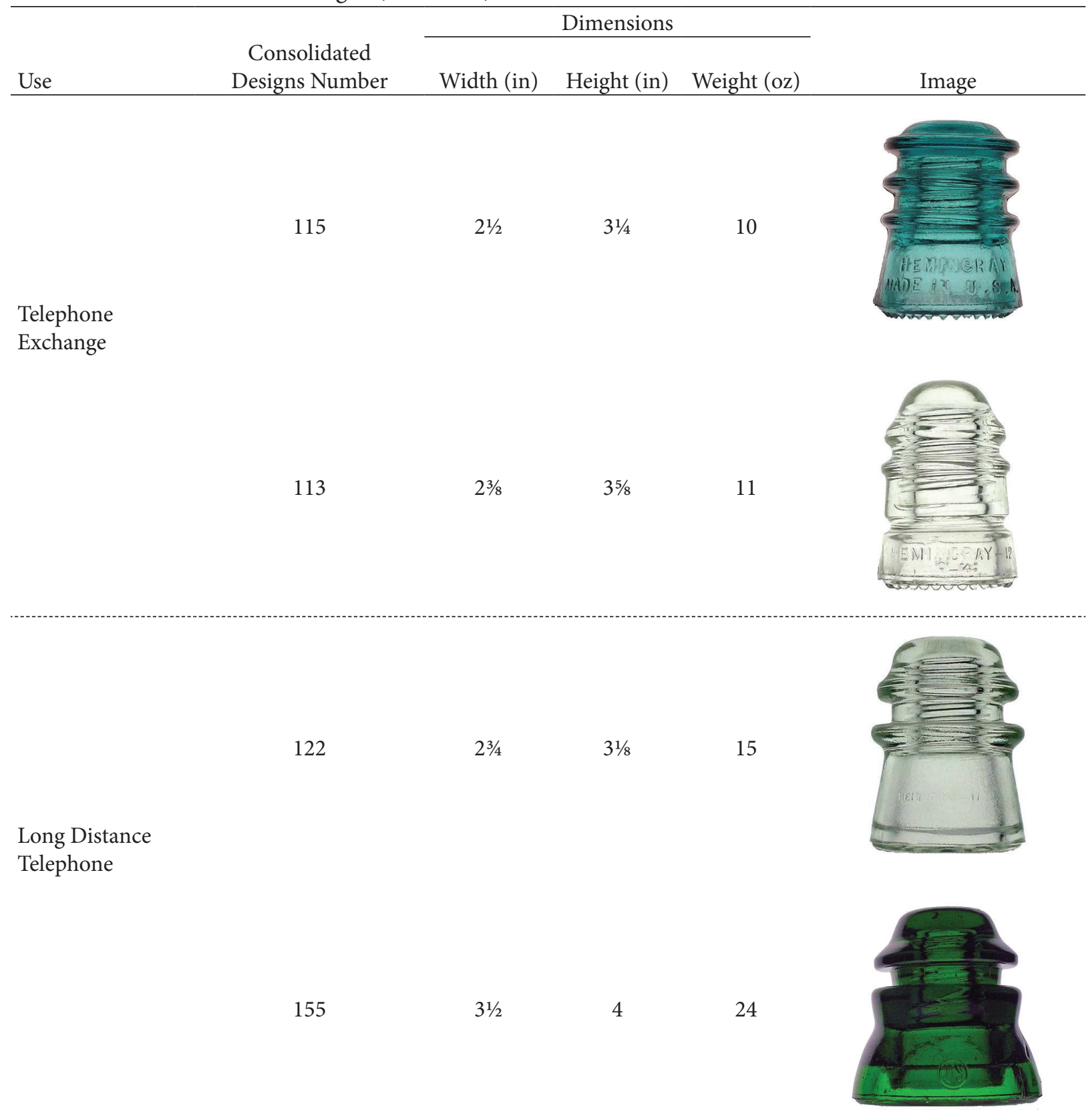

Notes. The use and dimension information are from the website: www.insulators.info (Meier 2009). Images are from the National Insulator Association's online insulator image gallery (NIA 2020). The Consolidated Designs (CD) numbering system was developed by N.R. Woodward (Hemingray Glass Company 2020). 
The same insulator could function for either communication method. The sheer number of insulator manufacturers within the U.S. alone makes cataloging all or even most stylistic changes among insulators beyond the scope of this research. A stylistic seriation of insulators would be a worthwhile and interesting project.

Poles

Poles are the most visible and identifiable features of historic telegraph and telephone lines. Pole locations and specifications are two types of evidence that could lead to determining which kind of communication system is represented.

Thorough documentation of pole locations and associated features could help identify their usage and the source and destination of the communication lines. Poles that follow current or former railroad lines could be for either telegraph or telephone systems and railroad company records and histories will provide useful information. When asked how to differentiate telephone and telegraph lines, nearly every insulator collector said that telegraphs followed the railroads. One collector stated that unlike the telegraph, which mostly followed the railroads, telephone lines were built over just about any type of terrain. Telegraph lines constructed before the arrival of a railroad were often later removed and placed on the railroad's right of way (King 1984:138). Placing a telegraph line on a railroad right of way provided ready access for maintenance and easy transportation of construction materials (Calvert 2006). Rather than obtaining multiple land easements from individual landowners, only a single agreement with a railroad company was necessary. Railroads, however, utilized their rights of way for telephones as well (BC 1922:20). Field documentation of all poles encountered can be used to determine the source and destination of a communication line. Identifying a source or destination narrows the scope of potential documentary sources, such as a local newspaper that mentions the line.

Pole specifications-height, diameter, and wood type-especially if uniform, may help distinguish between a line constructed by a major company or a smaller, more improvised mutual or rural line. The organization that constructed the line can be a clue to the type of line constructed, when combined with other information. For example, the 1891 American Telephone and Telegraph Company specifications stated that poles should be approximately 40 feet tall and 7 inches or more in diameter at the top (Rhodes 1929:97). The only tree species mentioned are cedar, with a minimum base diameter of at least 17 inches, and chestnut, with a minimum base diameter of 12 inches. Although their dimensions are unknown, pine and fir poles imported from the Pacific Northwest were also utilized in Colorado and other western states (DCL, BC 1902:41). To prevent poles from rotting and conducting a signal's electricity, poles needed to be seasoned, a process described by Calvert (2000). He states that poles were left in a seasoning pile for a minimum of six months to drain the sap. The bottom 5 or 6 inches of the poles were then charred and tarred before being placed in the ground. Calvert (2000), however, acknowledges that this process was not always followed in the U.S. and that those constructing telegraph lines often used unseasoned wood purchased from nearby farmers. If a set of poles on a communication line does not reasonably fit within these specifications, the possibility stands that it was part of a mutual or rural line that purchased or acquired materials locally. Differentiating telegraph and telephone poles based on their physical description alone should not be attempted, as both used similar, if not identical, poles (Saguache Chronicle, 16 February 1878).

Pins

Insulators have proven to be desirable commodities among collectors, as demonstrated by their vast number of publications and the wealth of knowledge gathered by individual collectors. This popularity increases the likelihood, should an archaeologist encounter a decommissioned communication line, that its insulators have been removed, leaving only the pins upon which they sat. Unfortunately, insulator pins have little to no diagnostic potential.

Pins acted as attachment points for insulators, as discussed above. Prior to Louis Cauvet's threaded insulator in 1865 (Cauvet 1865; Cleland 1983:6; Milholland and Milholland 1973:1; Miller et al. 2000:15) these pins were unthreaded, and insulators were attached using friction, often aided with the 
addition of burlap or tar (NIA 2020). It remains unclear whether pin or insulator threading affected compatibility with their non-threaded counterparts, though Bob Bunker (personal communication 2020) suggests there may have been pin hole size differences significant enough to prevent cross compatibility.

Non-threaded pins could be made of wood or metal. Though little literature focuses on the pins themselves, McDougald and McDougald (2013:210) describe several threadless insulator models, some of which utilized wooden pins whereas others utilized metal. Threaded pins could also be made of either material and often contained elements of both, though early availability of pins containing metal elements remains unclear (figures 14 and 15). The 1882 Western Electric Company catalog for the American Bell Telephone Company (1882:18), 1895 Montgomery Ward catalog (Emmet 1969:215), and 1897 Sears, Roebuck and Co. catalog (Israel 1968:471) all contain no mention of metal pins. The 1907 Western Electric Catalog of Telephonic Apparatus and Supplies (WEC 1907:129-131), however, contains both wooden and metal pins of multiple varieties. In his compilation of supply catalogs, Kareofelas (1969:105) also displays both threaded metal pins and a threaded wooden cob placed atop a carbon steel pin. Unfortunately, it is unclear which catalog this is from or when it was published, as Kareofelas (1969) compiled materials produced between 1917 and 1929. Prices of wooden and metal pins were not compared, as they were not listed in the Western Electric catalog (WEC 1907:129-131). Though prices are listed in Kareofelas' compilation, it is unclear whether the examples were from the same catalog, or even produced and sold the same year (Kareofelas 1969:102-106). Wooden pins by the thousand, however, were significantly lighter than those with metal components (WEC 1907:129). It is, therefore, possible that wooden pins were less expensive and easier to transport into remote areas.

The only other information that may be inferred from pin stems is from their arrangement on a crossarm. As pins were attachment points for insulators, they were also attachment points for wires. Thus, simple attributes, such as how many remain on a crossarm and their arrangement, may be used to infer how many wires were present, or even the presence of a metallic (two wire) telephone circuit (Bell 1879). Even so, we do not have enough information to make a strong case for pins as diagnostic artifacts.

\section{Electrical Transmission Lines}

Electrical power transmission systems also used poles, wires, and insulators. Although beyond the

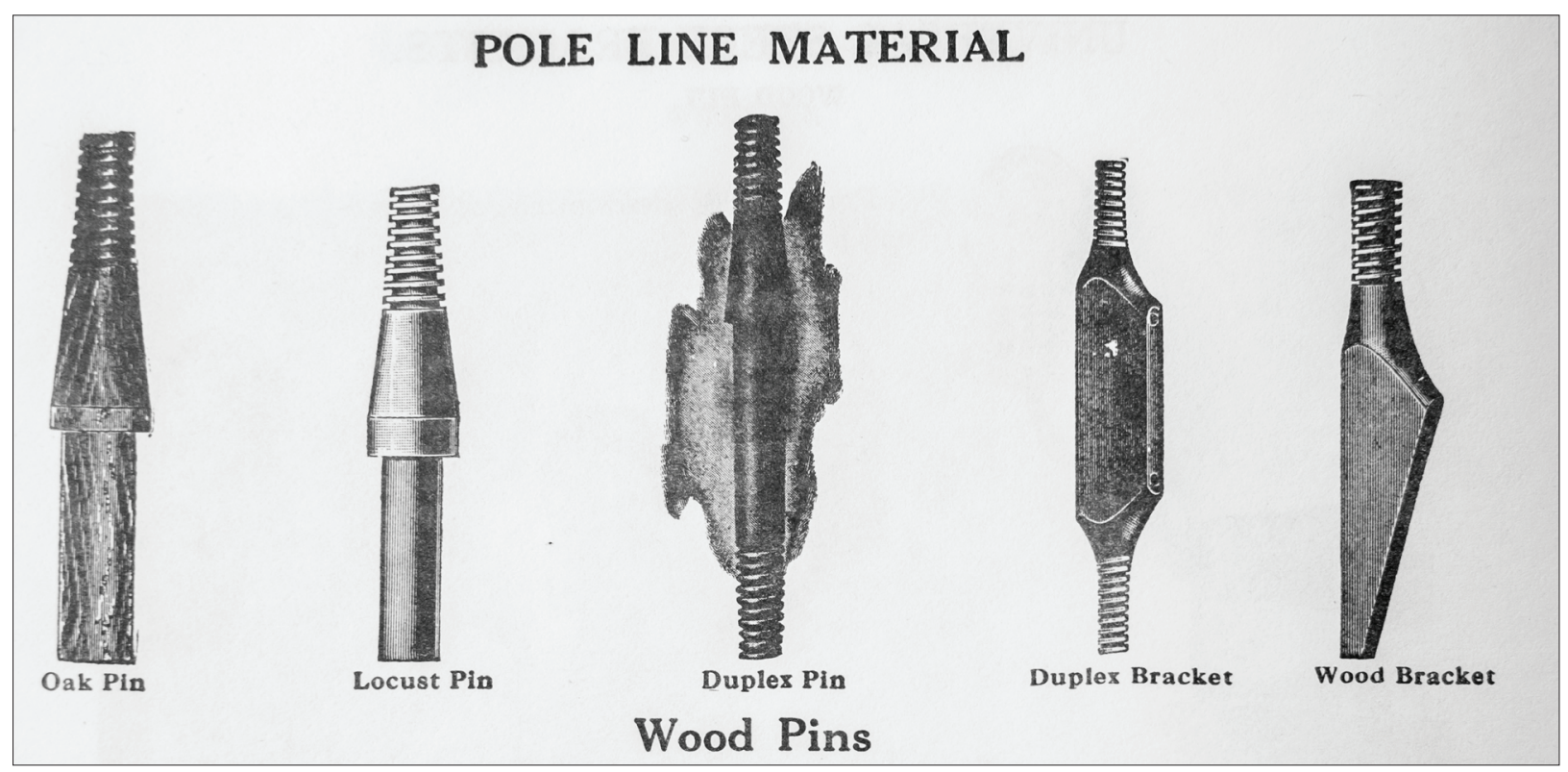

Figure 14. Supply catalogue images of various wooden pin styles (Kareofelas 1969:102). 


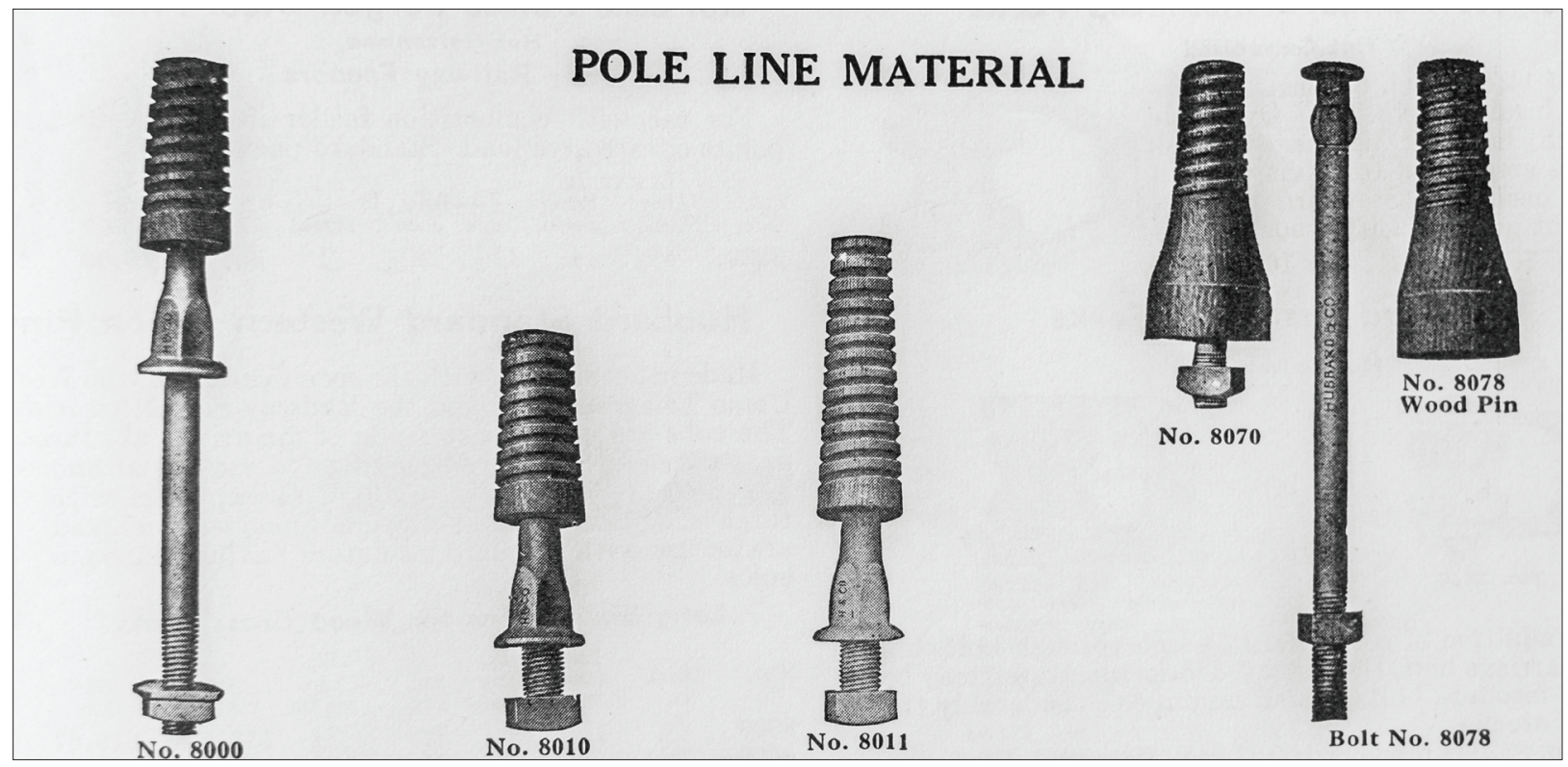

Figure 15. Supply catalogue images of metal pins with threaded wooden cobs (Kareofelas 1969:103).

scope of our study, we provide some guidance here to the similarities and differences with telegraph and telephone material culture.

The first use of electrical power in Colorado occurred on April 21, 1880 when an exhibition arc light plant was installed in Denver (Robertson 1982:3). In 1883, Leadville became the second town in Colorado to use arc lights. The first implementation of high voltage power transmission in Colorado took place in 1890-1891 at the Gold King mine in Telluride (Britton 1972). By 1885, the majority of nearby fuel sources (namely coal and wood) had been exhausted (Britton 1972:186) and transporting coal to an altitude of 12,000 feet was a costly endeavor (King 1984:75). Although hydroelectric power, a low-cost source of electricity, had been previously utilized by mines in Aspen and Ouray, the Gold King mine operated 2.6 miles from the nearest source of hydroelectric power, the south fork of the San Miguel river (Britton 1972:186-187; King 1984:75). To overcome this distance, the mine implemented one of the first alternating current, high voltage transmission lines in the U.S. (Britton 1972). The high cost of fuel transportation affected mines throughout the state, and the needs of miners served as a driving force that brought electric power to remote parts of Colorado (King 1984:75). King (1984:77) notes that "the adoption of electricity in Colorado was rapid and widespread. Major cities, towns, and mining areas in the mountains were often the first to electrify." (See King 1984:81 for a map of significant, early electrical developments in the state.)

Many elements of electrical transmission material culture are fundamentally similar if not identical to those associated with telephone and telegraph systems. For example, the insulators and crossarms used at the Gold King mine were the same as those used by the Western Union Telegraph Company (Britton 1972:190). Differentiation is further complicated by the fact that electrical transmission wires often occupied different crossarms of the same poles (Bob Bunker, personal communication 2020). Finding historic electrical transmission wires in the field, however, is unlikely because the copper frequently utilized in conductors was valuable (Jon Horn, personal communication 2020). In general, the most effective way to differentiate electrical transmission and communication lines is by observing the associated insulators.

Four primary characteristics differentiate electrical transmission insulators from communication insulators: size, material, shape, and color. In general, insulator size is directly correlated with line voltage (Johnson 2020; Bob Bunker, personal communication 2020). Thus, transmission insulators were larger than communication insulators. While electrical transmission insulators 
could be made of glass or porcelain, communication insulators were typically made of glass (Keane 2008; Kelley 1884:111). Electrical transmission insulators often had either a saddle groove-a U-shaped indentation on the top of the insulator for the wire (see table 2, Consolidated Designs 214 for an example [Bob Bunker, personal communication 2020]) - or a much wider area at the top to prevent high voltage current from arcing to the pole, labeled by Johnson (2020) as an umbrella disk.

Communication and transmission wires could occupy the same poles and use the same insulators (Bob Bunker, personal communication 2020). In such a case, Bunker states that glass transmission insulators were colored differently. This allowed a line repair worker to easily differentiate the communication and transmission lines and avoid accidental electrocution. Whereas communication insulators were shades of light blue and aqua typical of untreated glass, transmission insulators were colored cobalt blue and brown (Bob Bunker, personal communication 2020).

\section{Summary of Telegraph-Telephone Differences for Field Documentation}

Information differentiating historic telephone and telegraph systems and temporal information can be gathered from the poles, wires, insulators, and documentary records associated with these systems. We recommend thorough documentation of communication system materials identified in the field; supplement B provides a list of attributes to be documented. The potentially diagnostic attributes of the wires, insulators, and poles are summarized below.

- Wires are the most reliable way to tell the difference between the two technologies. Although wire material provides some temporal information, the organization of multiple wires into a metallic circuit is unnecessary for a telegraph and, thus, was primarily implemented in telephone systems. Document wire material type and the organization of the wires (package). A cross-section of cables will be helpful. An equidistant double-wire system more likely indicates a telephone system because the two-wire (metallic) circuit was designed for telephone systems, although they should also benefit the clarity of telegraph systems. A single-wire grounded system could indicate either a telegraph system or telephone system with limited users.

- Insulators may provide temporal information. Much like a glass bottle or tin can, different elements of insulator morphology, including drip points, threading, and various embossing patterns, can provide important temporal information. For example, if an archaeologist identifies a system where most of the insulators have drip points, it is reasonable to conclude the system was constructed after 1893 (Hemingray 1893). Using insulators to differentiate system type, however, is more difficult because insulators with the same physical attributes could function for both systems. Although Meier (2009) attempts to identify various styles of insulators as telephone or telegraph, no evidence suggests they were used exclusively for a particular type of system. Document all text and numbers on the insulator, their size and color, and the presence or absence of threads. Collector handbooks and websites and patent dates can identify when an insulator type was first manufactured, but many insulators had long use lives.

- Pole locations and standardized measurements can be diagnostic. Poles located near a railroad grade may indicate that it was associated with a telegraph system. Documentary records can be used to identify when the railroad was built and used, which could lead to identifying or inferring the type of communication system. Document any evidence of the standardization of pole sizes, materials, or treatments. Standardization could suggest specific manufacturers and uses. Thorough documentation of pole locations and associated features (especially those that are temporally diagnostic) could prove helpful to identify or infer the source and destination of the communication lines. Connecting a communication line to its source or destination can lead to specific documentary sources, such as a local newspaper that mentions the line.

- Any documentary records used to inform site or survey interpretations can be used for identifying telegraph or telephone lines. We recommend land ownership records including 
plat maps, work orders and line repair records, newspaper articles, and contact with local museum and historical societies. There are no master state maps of telegraph lines and there is a least one map of telephone lines in Colorado as of 1909 (figure 3; see also supplement A).

\section{Conclusions}

This article aims to describe the material record associated with historic telegraph and telephone lines and to facilitate their differentiation within Colorado. Even with excellent field recording of identified material culture, comparisons with the information provided in this article, and historical documentary research, differentiating between telegraph and telephone systems may not be possible. The challenges created by their temporal overlap and sometimes shared material culture are formidable. This is an important finding and contribution, however, because the similarities and differences of the material culture archaeologists are most interested in have not been previously compared or documented. Knowing that there are no easy solutions to differentiating telegraph and telephone systems in the field is important because it directs research efforts to where they will be most productive.

We agree with King (1984) in the Colorado Engineering Context-there are interesting and important questions to ask and current documentation of the early histories of the emergence of these technologies in Colorado is inadequate. Evidence of the location and spread of early telegraph systems is likely more abundant today in the field than in documentary records. Documenting differences in these systems so that archaeologists can accumulate spatial and temporal information of their spread and use is important, especially given the continued loss of these systems to land development, natural processes, and collecting. Modifications and additions to existing cultural resource survey and inventory forms is an effective step toward addressing the deficiencies in the historical record and providing future researchers with a valuable source of information. The material culture of these communication systems is not simply wires, poles, and insulators, but rather, the means to essential human connections. We have made progress on system identification and look forward to future progress by others.

Acknowledgments. We thank the USDA Forest Service and especially Angie Krall and Marcy Reiser for proposing and supporting the survey work that stimulated our interest in the research presented in this paper. We are also grateful for the financial support provided by the Forest Service through the cooperative grant agreement, "Colorado College Field Study on the Rio Grande National Forest." The focus of the grant is to identify portions of the "Old Spanish Trail." Financial support for the research was also provided by the Colorado College "Faculty-Student Collaborative Grant" program. We also thank Bob Bunker for sharing his knowledge and insights about insulators and inviting Birndorf to the $32^{\text {nd }}$ Annual Insulator, Bottle, Barbwire and Collectibles Show in Albuquerque, New Mexico in 2019.

\section{References Cited}

American Telephone and Telegraph Company

1910 Lines of the Bell Telephone Companies. United States and Canada. July 1, 1909. Heliotype Co., Boston. Electronic document, https://www.davidrumsey.com/luna/ servlet/detail/RUMSEY 8 1 200183 3000108:LinesOf-The-Bell-Telephone-Compani? sort $=$ Pub List No InitialSort\%2CPub Date\%2CPub List No\%2CSeries No\&qvq=q:telephone;sort:Pub List No InitialSort\%2CPub Date\%2CPub List No\%2CSeries No;lc:RUMSEY 8 1\&mi=18\&trs=39\#, accessed March 9, 2020.

Bell, Alexander G.

1879 Telephone Circuit. United States Patent and Trademark Office No. 220,791. Electronic Database, https:/pdfpiw.uspto.gov/.piw?Docid=220791\&idkey=N ONE\&homeurl=http\%3A\%252F\%252Fpatft.uspto.gov \%252Fnetahtml\%252FPTO\%252Fpatimg.htm, accessed February 12, 2020.

1881 Telephone-Circuit. United States Patent and Trademark Office No. 244,426. Electronic database, https://pdfpiw.uspto.gov/.piw?PageNum $=0 \&$ docid $=00244426 \&$ IDKey $=$ FB6DD $6977528 \%$ 0D\%0A\&HomeUrl=http\%3A\%2F\%2Fpatft.uspto. gov\%2Fnetahtml\%2FPTO\%2Fpatimg.htm, accessed February 12, 2020.

Boris, Emmet

1969 Montgomery Ward \& Co: Catalogue and Buyers Guide No. 57, Spring and Summer 1895. Dover Publications, New York.

Britton, Charles C.

1972 An Early Electric Power Facility in Colorado. The Colorado Magazine 49(3):185-195. https:// www.historycolorado.org/sites/default/files/media/ document/2018/ColoradoMagazine v49n3 Summer1972.pdf, accessed May 23, 2020.

Brookfield, William

1871 Improvement in the Modes of Making Telegraph- 
Insulators. United States Patent and Trademark Office No. 113,393. Electronic Database, https://pdfpiw.uspto. gov/.piw?Docid=113393\&idkey=NONE\&homeurl=http \%3A\%252F\%252Fpatft.uspto.gov\%252Fnetahtml\%252F PTO\%252Fpatimg.htm, accessed February 12, 2020.

Brooks, Homer

1870 Improvement in the Manufacture of Insulators for Telegraph-Poles. United States Patent and Trademark Office No. 99,145. Electronic Database, https://pdfpiw. uspto.gov/.piw?PageNum=0\&docid=00099145\&IDKey= CEA9083D0DBE\%0D\%0A\&HomeUrl=http\%3A\%2F\%2 Fpatft.uspto.gov\%2Fnetahtml\%2FPTO\%2Fpatimg.htm, accessed February 12, 2020.

Bureau of Land Management [BLM, GLO]

2020 General Land Office Records. Electronic database, https://glorecords.blm.gov, accessed April 6, 2020.

Calvert, James B.

2000 The Electromagnetic Telegraphy. Electronic document, https://mysite.du.edu/ jcalvert/tel/morse/ morse.htm, accessed February 12, 2020.

Cauvet, Louis A.

1865 Improvement in Insulators for Telegraph-Wires. United States Patent and Trademark Office No. 48,906. Electronic Database, https://pdfpiw.uspto.gov/.piw?P ageNum $=0 \&$ docid $=00048906 \&$ IDKey $=624$ B6B91154 C\%0D\%0A\&HomeUrl=http\%3A\%2F\%2Fpatft.uspto. gov\%2Fnetahtml\%2FPTO\%2Fpatimg.htm, accessed February 12, 2020.

Clark, Bonnie J., and Kathleen Corbett

2007 Settlements. In Colorado History: A Context for Historical Archaeology, by Minette C. Church, Steven G. Baker, Bonnie J. Clark, Richard F. Carillo, Jonathan C. Horn, Carl D. Späth, David R. Guilfoyle, and E. Steve Cassells, pp. 107-151. Colorado Council of Professional Archaeologists. Denver, Colorado.

Cleland, Charles

1983 A Computer Compatible System for the Categorization, Enumeration, and Retrieval of Nineteenth and Early Twentieth Century Archaeological Material Culture. Manual for Identification and Classification Part II. Michigan State University. East Lansing, Michigan.

Collectors Weekly

2020 Vintage Glass Insulators. Electronic document: https://www.collectorsweekly.com/tools-and-hardware/ insulators, accessed April 6, 2020.

Colorado Daily Chieftain [Pueblo, Colorado]

1899 "Mussed Up The Floor." 28 June. Pueblo, Colorado. Colorado Historic Newspaper Collection, https://www.coloradohistoricnewspapers. org $/ ? \mathrm{a}=\mathrm{d} \& \mathrm{~d}=\mathrm{CFT} 18990628-01.2 .62 \& \operatorname{srpos}=14 \& \mathrm{e}=26-$ 06-1899-27-06-1900--en-20--1- - imgtxIN\%7ctxCO\%7ctxTA-valverde-------0---- \%2c-1, accessed December 1, 2020.

Colorado State Library

2020 Colorado Historic Newspaper Collection. Electronic Database, https://www.coloradohistoricnewspapers.org, accessed February 12, 2020.

Copper Development Association Inc. [CDA]

2020 The Evolution of Telephone Cable. Electronic document, https://www.copper.org/applications/ telecomm/consumer/evolution.html, accessed February 12, 2020.

Denver Public Library

2020 Howard T. Vaille, Biographical/Historical. Electronic document https://archives.denverlibrary.org/ repositories/3/resources/5458, accessed 18 April 2020.

Department of Commerce and Labor Bureau of the Census [DCL, BC]

1902 Special Reports: Telephones and Telegraphs. Government Printing Office, Washington. Electronic document, https://catalog.hathitrust.org/ Record/101736293, accessed May 23, 2020.

Department of the Bureau of the Census [BC]

1922 Census of Electrical Industries: Telegraphs. Government Printing Office, Washington. Electronic document, https://babel.hathitrust.org/cgi/pt?id=mdp. $\underline{39015028113507 \& v i e w=2 \text { up\&seq }=6}$, accessed May 23, 2020.

Dolores News [Dolores Colorado]

1879 "News Regarding Telegraph Line Construction". 28 August. Dolores, Colorado.

Hackenburg, Herbert J.

1986 Muttering Machines to Laser Beams: A History of Mountain Bell. Mountain Bell, Denver.

Hemingray Glass Company

2020 All Insulators Crown Jewels of the Wire, About CD System (created by N.R. Woodward). Electronic document, https://allinsulators.com/photos/glass/ CD/\#fndtn-tab2, accessed July 20, 2020.

Hemingray, Robert G.

1871 Improvement in Molding Telegraph-Insulators. United States Patent and Trademark Office No. 122,015. Electronic Database, https://pdfpiw.uspto.gov/.piw?Doci $\mathrm{d}=122015$ \&idkey=NONE\&homeurl=http $\% 3 \mathrm{~A} \% 252 \mathrm{~F} \% 2$ 52Fpatft.uspto.gov\%252Fnetahtml\%252FPTO\%252Fpat img.htm, accessed March 1, 2020.

Hemingray Robert G., and James C. Gill

1893 Insulator for Telegraph Wires. United States Patent and Trademark office No. 496,652. Electronic Database, https://pdfpiw.uspto.gov/.piw?.Docid=496652\&idkey=N ONE\&homeurl=http\%3A\%252F\%252Fpatft.uspto.gov \%252Fnetahtml\%252FPTO\%252Fpatimg.htm, accessed March 1, 2020.

Hill, James Leander

1968 An Insulaor Book For Collectors: Sketches and Prices. Mail Printers, Myrtle Creek, Oregon.

Israel, Fred. L.

19681897 Sears Roebuck Catalog. Chelsea House Publishers, New York.

Johnson, Craig

2020 What the Heck Are Insulators? Electronic document, https://www.myinsulators.com/downtownseattle/ project.htm, accessed May 23, 2020.

Kareofelas, Greg A.

1969 A Catalogue and Reference to Insulators and Other Related Materials. Ole Empty Bottle House Publishing Company, Amador City, California.

Keane, Maribeth

2008 Ian Macky Explains the Colors and History of Insulators. Electronic document, https://www. 
collectorsweekly.com/articles/an-interview-withantique-glass-insulator-collector-ian-macky, accessed May 23, 2020.

Kelley, J. F.

1884 Porcelain Insulators. Electric World 3:111. Electronic document, https://babel.hathitrust.org/cgi/pt

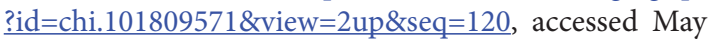
23, 2020.

King, Joseph E.

1984 Colorado Engineering Context. Colorado Historical Society, Denver.

Lockhart, Bill, Beau Schriever, Bill Lindsey, Carol Serr, and Bob Brown

2020 Western Glass Mfg. Co. Electronic document, https://sha.org/bottle/pdffiles/WesternGlass.pdf, accessed December 2, 2020.

Library of Congress

2020 Telephone and Multiple Telegraph, https://www.loc. gov/collections/alexander-graham-bell-papers/articlesand-essays/telephone-and-multiple-telegraph, accessed February 12, 2020.

Mahan, Bill

1975 The Telegraph in Southern Colorado 1867-1881. The San Luis Valley Historian 7(2):5-10.

Martin, Bernice

1990 Frontier Eyewitness: The Diary of John Lawrence 1867-1908. Colorado Endowment for the Humanities, Colorado.

McDougald, John and Carol McDougald

2013 Insulators: A History and Guide to North American Glass Pintype Insulators, Vol. 1. National Insulator Association. Electronic document, https://www.nia.org/ history and guide/Glass Pintype Insulators Vol 1.pdf

McQuarrie, J.L.

1911 Telegraph and Telephone Age: Telegraphy-TelephonyRadio. J. B. Taltavall. Electronic document, https://babel. hathitrust.org/cgi/pt?id=uiug. $30112111039498 \& v i e w=1$ up\&seq $=529$, accessed July 1, 2020.

Meier, Bill

2009 Insulator Profiles. Electronic document, https:// www.insulators.info/general/profiles, accessed February 12, 2020.

Milholland, Marion, and Evelyn Milholland

1973 Glass Insulator Reference Book. $2^{\text {nd }}$ ed. Pen Print, Los Angeles, California.

Miller, George L., Patricia Samford, Ellen Shlasko, and Andrew Madsen

2000 Telling Time for Archaeologists. Northeast Historical Archaeology 29(2):1-22.

Miller, Mike, and Tom Katonak

2005 The Western Glass Manufacturing Company. Electronic document. https://www.cjow.com/archive/ article.php? month $=6 \& \mathrm{a}=06 \mathrm{The} \% 20$ Western $\% 20$ Glass \%20Manufacturing\%20Co.htm \&year $=2005$, accessed December 2, 2020.

2005 The Western Glass Manufacturing Company. Electronic document. https://www.cjow.com/archive/ article.php? month $=7 \& \mathrm{a}=07$ The $\% 20$ Western $\% 20$ Glass\%20Manufacturing\%20Company.htm\&year $=2005$, accessed December 2, 2020.
Mitchell, Mark D.

2018 Introducing Reviews in Colorado Archaeology, a New Online Journal for Archaeological Research and Cultural Resources Management. Reviews in Colorado Archaeology 1(Article 1):1-9 DOI:10.32946/ RCA.2018.0001, accessed May 5, 2020.

National Insulator Association (NIA)

2020 Threaded Glass Insulators from North America. Electronic document, https://www.nia.org/general/g natpt.htm, accessed February 12, 2020.

Robertson, Lawrence M.

1982 The Birth and Growth of Electricity in Colorado: The Early Years 1880 to 1940. IEEE Power Engineering Review PER-2(1):3-8, DOI:10.1109/MPER.1982.5519652, accessed July 11, 2020.

Saguache Chronicle [Saguache, Colorado]

1878 "Article regarding the articles of incorporation for a telephone in Saguache." 16 February. Saguache, Colorado. Colorado Historic Newspaper Collection, https://www.coloradohistoricnewspapers.org/?a=d\&d $=\mathrm{SQC} 18780216.2 .33 \& \operatorname{srpos}=1 \& \mathrm{e}=--1878---1878-$-en 20--1--img-txIN\%7ctxCO\%7ctxTA-telephone-------0Saguache-, accessed May 21, 2020.

Schiffer, Michael B.

2017 Strong Cases and the Historical Record: The Case of Portable Radios with Subminiature Tubes. In The Strong Case Approach in Behavioral Archaeology, edited by Michael B. Schiffer, Charles R. Riggs, and J. Jefferson Reid, pp. 158-164. University of Utah Press, Salt Lake City.

Silver World [Lake City, Colorado]

1881 "News Regarding Construction of a Telephone Line." 11 June. Lake City, Colorado.

Späth, Carl

2007 Linear Resources. In Colorado History: A Context for Historical Archaeology, by Minette C. Church, Steven G. Baker, Bonnie J. Clark, Richard F. Carillo, Jonathan C. Horn, Carl D. Späth, David R. Guilfoyle, and E. Steve Cassells, pp. 387-424. Colorado Council of Professional Archaeologists. Denver, Colorado.

Rhodes, Frederick L.

1929 Beginnings of Telephony. Harper and Brothers Publishers, New York.

Stone, Wilbur F.

1918 History of Colorado, Vol. 1. S.J. Scott Publishing Company, Chicago.

Vaille, Howard T.

1916 History of the Telephone in Colorado. Manuscript on file, The Telecommunications History Group, Denver, Colorado.

West, Elliot

2012 Wired to the World: The Telegraph and the Making of the West. In The Essential West: Collected Essays, pp. 78-99. University of Oklahoma Press, Norman.

Western Electric Company (WEC)

1882 American Bell Telephone Co. Western Electric Company, Indianapolis. Electronic document. https:// www.telephonecollectors.info/index.php/browse/ document-repository/catalogs-manuals/bell-system-we/ we-catalogs/11183-1882-western-electric-catalogue- 
Tangled Transmissions

reprint-ocr-r/file, accessed December 1, 2020.

1907 Catalog of Telephonic Apparatus and Supplies. Western Electric Company, New York. Electronic document. https://www.telephonecollectors.info/index. $\mathrm{php/browse/document-repository/catalogs-manuals/}$ bell-system-we/we-catalogs/11201-1907ca-wecotelephonic-apparatus-and-supplies-catalog-ocr-r-largefile/file, accessed December 1, 2020.

1916 Catalog of Telephone Apparatus and Supplies NO. 3. Western Electric Company, New York. Electronic document, https://www.telephonecollectors.info/index. $\mathrm{php} /$ browse/document-repository/catalogs-manuals/ bell-system-we/we-catalogs/12240-1916-we-catalog-no3-telephone-apparatus-and-supplies-ocr-r/file, accessed December 1, 2020.

Willis, Christian E.

2019 Hemingray Embossing Styles. Electronic document, http://www.hemingray.info/database/embossingstyles. $\underline{\text { html, accessed February 12, } 2020 .}$

\section{Supplementary Material}

Supplementary Resource A: Link to Map of American Bell Telephone and Telegraph Company local and long-distance lines in the U.S. (https://www.davidrumsey.com/luna/servlet/ s/49el0z)

Supplementary Document B: Recommended Field Documentation of Communication System Material Culture and Notes on Interpretation (Adobe PDF, 782KB; https:// archaeologycolorado.org/sites/default/files/Birndorf-andIngram-2020-Supplement-B.pdf)
Birndorf and Ingram

\section{Contributor Notes}

Joshua Birndorf earned his Bachelor of Arts in Anthropology from Colorado College in Colorado Springs, Colorado and is currently serving as the Paraprofessional for the Department of Anthropology. Joshua has participated in several cultural resource survey and excavation projects in Colorado and focused on archaeology as an undergraduate. Research for this paper began as Joshua's undergraduate thesis project and was presented at the Annual Meeting of the Colorado Council of Professional Archaeologists in 2019.

Scott E. Ingram is an Assistant Professor of Archaeological Anthropology at Coorado College. He earned his Ph.D. from Arizona State University with a focus on the 700 to $1500 \mathrm{CE}$ period in the US Southwest. Research interests include climatic influences on human behavior, vulnerability and resilience to natural hazards, dendrochronology, dendroclimatology, and the historical archaeology of Colorado and New Mexico. Most work involves applications of archaeology to contemporary socio-environmental issues. (www.scottingram.net) 